
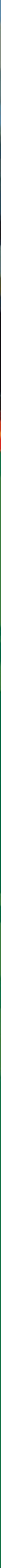
9

\section{Fire risk in Aboriginal peri-urban landscapes in northern Australia: Case studies from western Cape York Peninsula}

\section{Jim Monaghan}

This chapter focuses on characterisation of the peri-urban areas of remote Aboriginal communities in northern Australia; fire behaviour and the fire risks associated with Aboriginal peri-urban landscapes; and the sociopolitical and infrastructural aspects of remote Aboriginal communities that are relevant to fire hazard management.

In particular, it focuses on Pormpuraaw and Kowanyama as these towns have been a subject of research by the author for more than 12 years; more than five years of this time having been spent living and working in both communities (Figure 9.1).

The three main forms of Aboriginal settlement in rural northern Australia are Aboriginal towns, town camps, and Aboriginal communities.

Aboriginal towns include places such as Fitzroy Crossing in Western Australia; Borroloola in the Northern Territory; and Coen, Normanton and Chillagoe in northern Queensland. They are small towns with populations of no more than 2,000 of whom the majority are Aborigines, and their economies are based largely on welfare payments.

Town camps are features of the larger Northern Territory towns of Darwin and Alice Springs; their residents are people from outlying Aboriginal communities, and they come and go on an intermittent basis. Some residents are people who have been left stranded in town after hospital treatment or after having completed custodial sentences, others have been ostracised from their communities, and others are drug and alcohol dependant people. Some camps are permanent and have their own services. Temporary 'drinking' camps arise in parks and other public urban spaces in Cairns and Townsville in North Queensland. 
Aboriginal communities are settlements that commenced as church missions in the latter nineteenth and early twentieth century. The main reason for their establishment was concern about the effects of the pastoral, mining and fishing industries on the survival and well being of Aboriginal people in the north (Kidd, 1997; Loos, 1982). The population of these settlements is largely of traditional owners of the country in which the community is located, and also of 'historical' or 'diaspora' people who have been relocated, mostly under duress, to these settlements by the implementation of Queensland Government policy throughout the twentieth century.

Historically people may assert interests in 'community' country, even though they have no traditional affiliation to it, which are based on the precedent of their use of the country in recent generations and on the contingencies of State government legislation in the 1970s and 1980s which emphasised community land as a kind of generic 'Aboriginal' land rather than a domain which is subject to the traditional protocols of land allocation practice that are based on clan and kin affiliation. The influence of 'historical' people in community political life and community land management issues is greater on the east coast of Queensland in Aboriginal communities such as Hope Vale, Yarrabah, Palm Island and Woorabindah; their influence in the more remote areas of south-western Cape York Peninsula in communities such as Kowanyama, Pormpuraaw or Aurukun is negligible.

The larger missions in Queensland received Deed of Grant in Trust' (DOGIT) tenure from the State government in 1968 and most of these areas came under State administration at about that time. There are 15 DOGIT communities in mainland Queensland whose occupants, other than some Council or Shire staff and service providers such as nurses; teachers or police, are entirely Aboriginal communities. The Queensland Government transferred trusteeship of the DOGIT tenure to locally elected Community Councils in 1987. The Aboriginal Communities (J ustice and Land Matters) Act 1984 (Queensland Government, 1984; previously the Community Services (Aboriginal) Act 1984) defines the roles and responsibilities of the Community Council and its powers to create byelaws. 


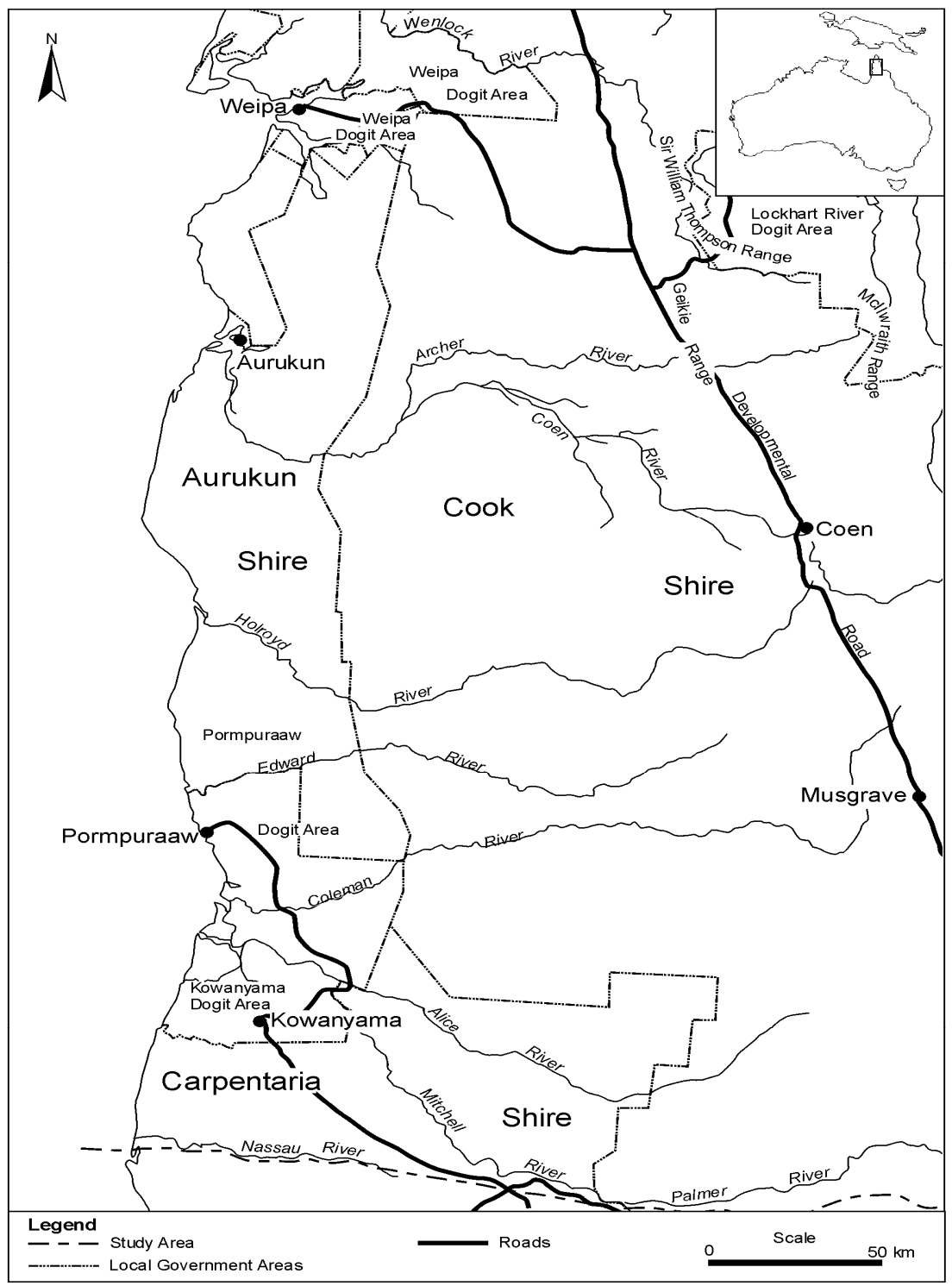

Figure 9.1

Western Cape York Peninsula

Source: Connell Wagner, 1989

The Queensland Department of Communities (previously the Department of Family and Community Services) audits council finances each year. Each council is also a member of the Queensland Aboriginal Coordinating Council (ACC). The ACC comprises representatives of all of the Aboriginal DOGIT communities in the State and is a forum within which the Queensland government develops policy for these communities. There are also 18 Torres Strait Islander DOGIT communities which are served by another 
Coordinating Council. The Community Council comprises seven members who are elected every three years. They are served by a clerk who is also chief executive officer with a staff of about 30 people who provide financial administration, parks and environmental health, and building and engineering services that are typical of a local government authority. Unlike local government authorities elsewhere in Queensland, DOGIT councils do not have any legal obligation to the requirements of the Integrated Planning Act 1997 (Queensland Government, 1997) and hence do not have any formal planning function to deal with infrastructure, environment, or land use planning issues (Monaghan \& Taylor, 1993).

\section{The geography of Aboriginal peri-urban landscapes}

Many DOGIT communities are experiencing considerable development of their hinterland since the Aboriginal Land Act 1991 (Queensland Government, 1991), the Native Title Act 1993 and the Native Title Amendment Act 1998 (Commonwealth of Australia; 1993, 1998) have provided mechanisms for traditional owners to make either land or native title claims to their traditional country, and are developing peri-urban characteristics. Some townships are developing as centres around which a constellation of residential, smallholding and rural enterprise settlements are growing with the township providing retail store, fuel, and police, health and education services. The geography of Aboriginal peri-urban areas is determined by a number of factors including historical land use trends and the location of the township in relation to the traditional country of origin of its inhabitants and the jural and proximal entitlements (Sutton, 1998) that are asserted by local people to urban hinterland country (Monaghan, 2005).

\section{Historical land use trends in Aboriginal northern Australia}

Most of northern Australia has a highly seasonal environment with marked wet and dry seasons. Prior to European colonisation, Aboriginal people lived a nomadic existence based on movement that followed socially and environmentally prescribed routes around the wet and dry season landscapes. The social organisation of these routes was based on primary and secondary rights of ownership or land use under the 'clan estate' and 'range' systems of socio-spatial organisation respectively (Stanner, 1965). Each person had a distinct suite of rights of ownership or access to the natural and spiritual resources of particular tracts of landscape depending on their status within the local kinship and clan totemic systems that determine the distribution of primary and secondary rights. Primary or clan affiliation rights are based on patrilineal descent systems and embody notions of land ownership. Secondary rights are kinship based and relate to rights of natural resource use (Stanner, 1965). 
With the arrival of European pastoralists and missionaries into Aboriginal country in the latter nineteenth century and early years of the twentieth century, a process of 'centralisation' took place with the movement of Aboriginal people into the missions or cattle stations that were established in their country. This led to the development of a set of socio-spatial relations amongst Aboriginal people which was based on whether their traditional country was 'inside' or 'outside' the newly established settlements (Anderson, 1988; Freier, 1999; Gribble, 1933; Monaghan, 2003a; Smith, 2000; Strang, 1994). Terms such as 'myalls', 'station blacks' and 'mission blacks' were used to refer to Aboriginal people on the basis of their origins and locations (Monaghan, 2005). These features are further reflected in the spatial and social organisation of households and neighbourhoods in Kowanyama and Pormpuraaw (Taylor, 1979; Monaghan, 2003a, 2005).

Access to traditional country from the mission settlement was at least allowed and in many cases was encouraged by church missions which were often not in the position to be able to supply their residents with food rations because of their poor financial circumstances: hunting and gathering activities continued to be an important form of subsistence for mission residents (Kidd, 1997; Taylor, 1984).

The years of Queensland State administration, from the mid-1960s to the latter 1980s, were characterised by a policy of 'assimilation' and a more enforced centralisation of what were now called communities, following the Aborigines and Torres Strait Islanders (Land Holding) Act 1985 (Queensland Government, 1985); and land use and access to traditional country was actively discouraged by State administration officers (Kidd, 1997). This prohibition was less so in the more remote communities such as Pormpuraaw and Kowanyama in western Cape York Peninsula where the distance from Brisbane led to the development of a more tolerant relationship between local people and the government officers who superintended their affairs (Monaghan, 2005). For instance, 'holidays' in the dry season landscape were still common in Pormpuraaw throughout the 1970s and 1980s with families living in temporary camps out in the bush for weeks on end (Taylor, 1984). Nonetheless, the Uniting Church was removed by the Queensland Government from their management of the Aurukun and Mornington Island communities in 1978 because of their active support for local groups who were setting up outstations in their traditional country (Kidd, 1997).

DOGIT communities became autonomous with the transfer of DOGIT title from the trusteeship of the State to that of locally elected community councils in 1987. The Aboriginal Land Act 1991 (Queensland Government, 
1991), the Native Title Act 1993 and the Native Title Amendment Act 1998 (Commonwealth of Australia; 1993, 1998) have accelerated the 'return to country' movement which had gathered momentum through the latter 1980s and early 1990s. There are 13 outstations that have been established in Pormpuraaw since 1989; and 22 that have been set up in Kowanyama since 1997. Outstations are the main features of the peri-urban landscape, which are now emerging around Aboriginal communities; they are small settlements that are located in the traditional country of their residents and are mainly occupied in the dry season, which is also the time of the greatest fire risk in the landscape.

\section{Structural features of Aboriginal peri-urban landscapes}

The main structural features of Aboriginal peri-urban landscapes are the immediate town hinterland area, dinner camps, camp sites and outstations.

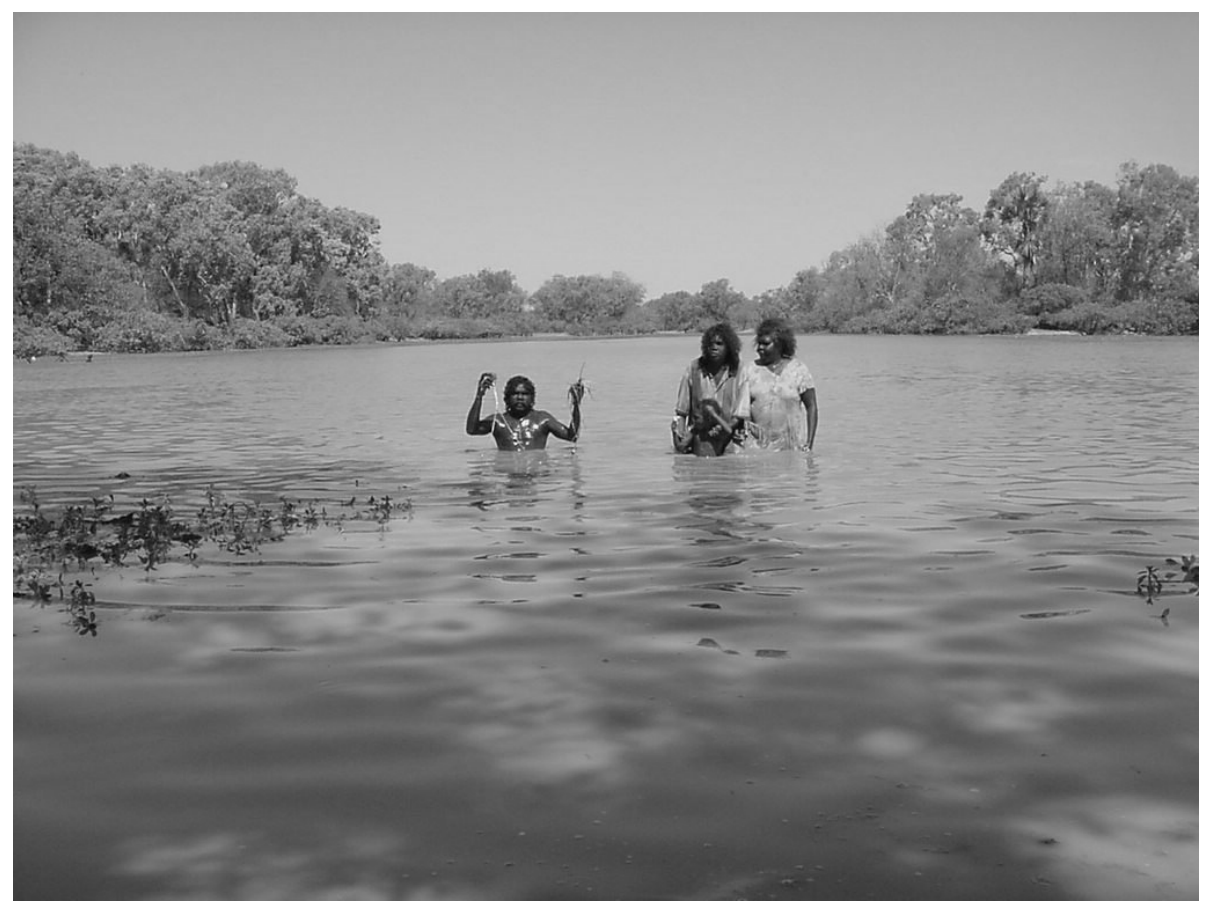

Figure 9.2 Magkara Lagoon is a popular dry season fishing place in the Kowanyama hinterland Source: Kowanyama Collection 


\section{Town and hinterland}

The hinterland is that tract of landscape around the township that people can access year round without the need for a motor vehicle. It is the area where people will go to hunt or to forage for fruits and bird eggs; in many respects it is the community larder' and an important source of protein which is often expensive to purchase at the community store or which might be in short supply in the wet season. It is also a recreational area where families will camp out for a night or for a weekend. With an extensive wet season the hinterland is inevitably smaller than in the dry season and extends over the area where water is shallow enough for people to walk or wade out to at that time of the year.

\section{Dinner camps}

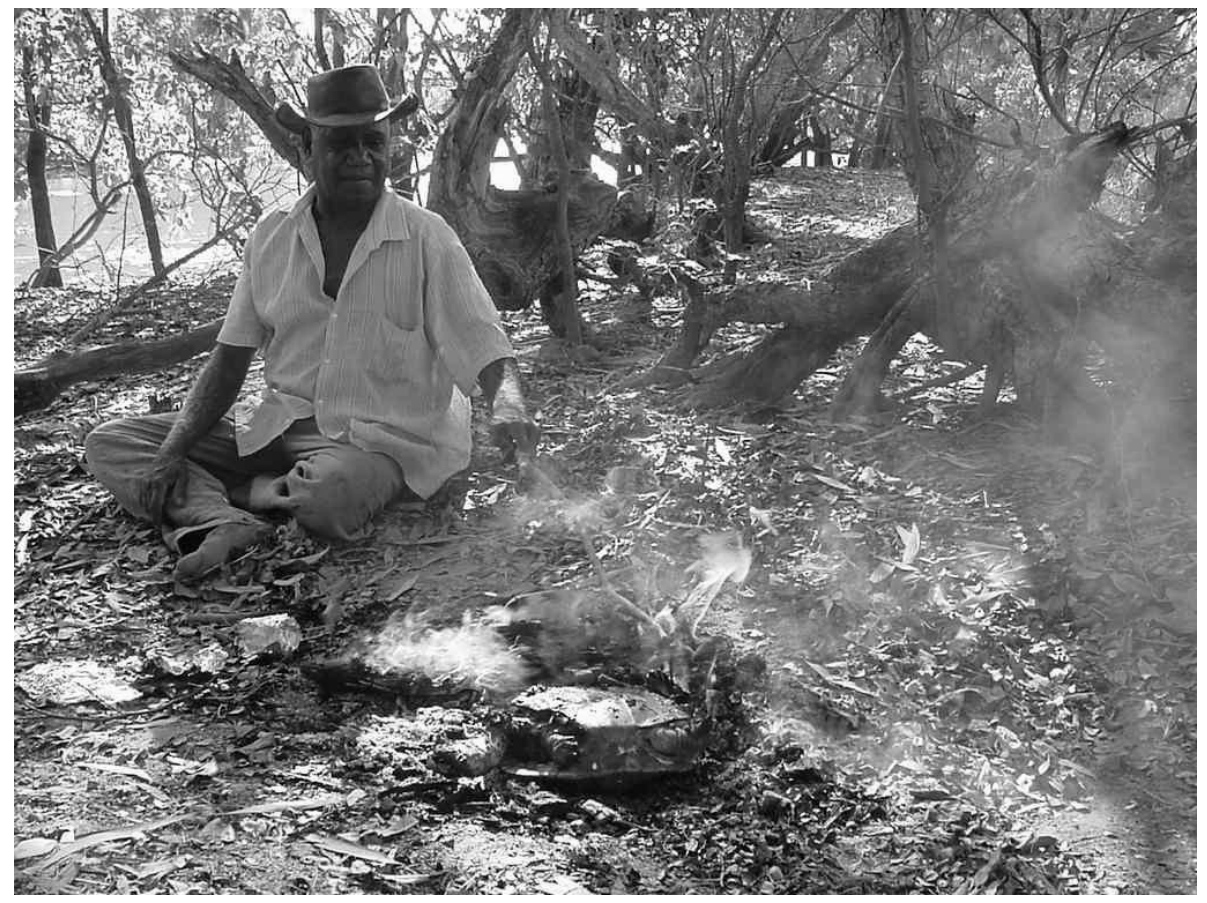

Figure 9.3 Open fire cooking Source: Kowanyama Collection

Dinner camps are places where people will stop and cook their catch when they have been out on fishing or hunting trips (Figures 9.3 and 9.4). They are most frequently found near shady areas or rivers but are found throughout the landscape. They usually comprise a kup murri' cooking pit which is up to $1.5 \mathrm{~m}$ long along the main axis and about $0.50-0.75 \mathrm{~m}$ deep. A fire is lit to make coals and these are placed in the bottom of the pit and the food placed 
on top. In turn, the food is covered with either pandanus leaf or melaleuca bark, or sheets of corrugated iron; and earth placed on top of this covering. Food cooks very quickly in these ground ovens and a dinner camp stop where food is cooked, consumed, digested and the camp remains then cleared away is usually of no more than three or four hours duration. Despite their transitory nature, dinner camps may be longstanding features in some places because of the local availability of cooking materials, or the proximity of good fishing opportunities.

Figure 9.3 shows Edmund Eric, a Kokoberra Elder, cooking a turtle at an open fire and Figure 9.4 shows Yvonne Jimmy and Ezra Michael, who are Kokomunjen [Yir Yoront] elders, ensuring that a kup murri pit has been completely extinguished.

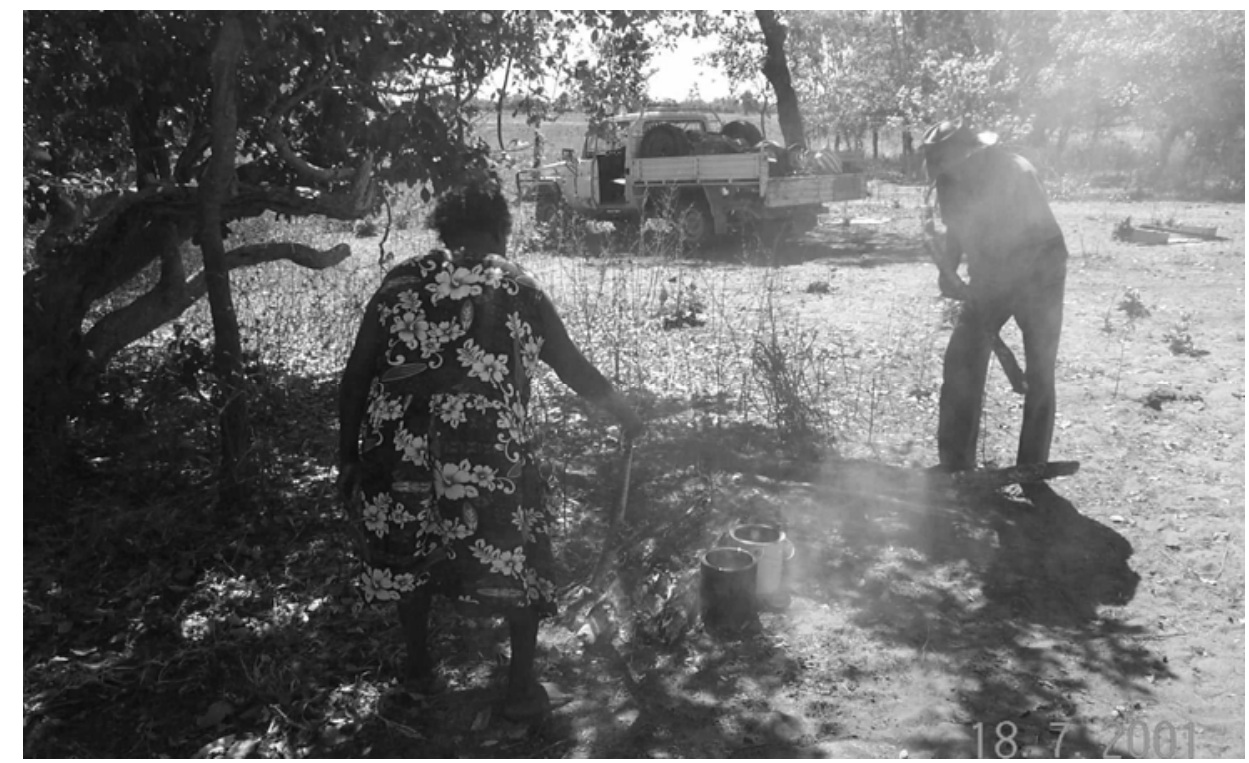

Figure 9.4 Tending to a kup murri pit Source: Kowanyama Collection

\section{Campsites}

Campsites are found throughout the dry season landscape usually at locations where cattle infrastructure affords shelter and at traditional places which form the core of traditional homeland country (Figures 9.5 and 9.6). Many are in abandoned cattle yards where fencing still exists or timber is available from derelict yard buildings, or they are adjacent to lagoons. They usually comprise shelters constructed from 'star pickets' or fencing posts and blue tarpaulin, with bed frames or breeze-block bases and old sink units supported by timber frames providing the furniture (Monaghan, 2005). 


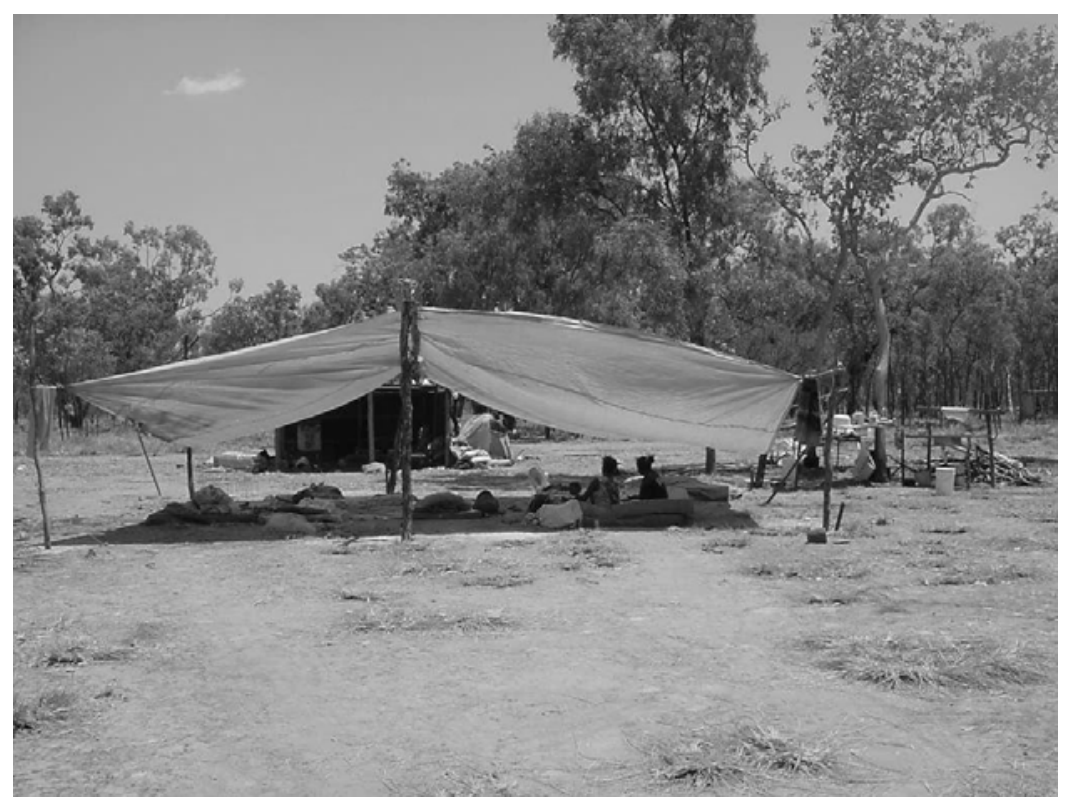

Figure 9.5 A dry season camp site Source: Kowanyama Collection

Families will holiday at campsites for many weeks on end. Children and old people are the main occupants during the week as many working-age adults are at work in the township and they join their families at the weekend. Truancy levels at community schools are very high in the dry season. Some campsites are considered community places because of their longstanding and school camps are held at them during National Aboriginal and Islanders Day Observance Committee (NAIDOC) week. There are, for instance at Kowanyama, four or five nodal campsites each of which, because of their location, has a distinct tribal or language group association and school camps are held at each of these sites for children from that respective background. Other campsites, which are usually close to town, are occupied by families who have camped there for many years, even though they have little traditional association with the campsite, they may be given permission to have their own camp site because their own traditional country is a long distance away. 


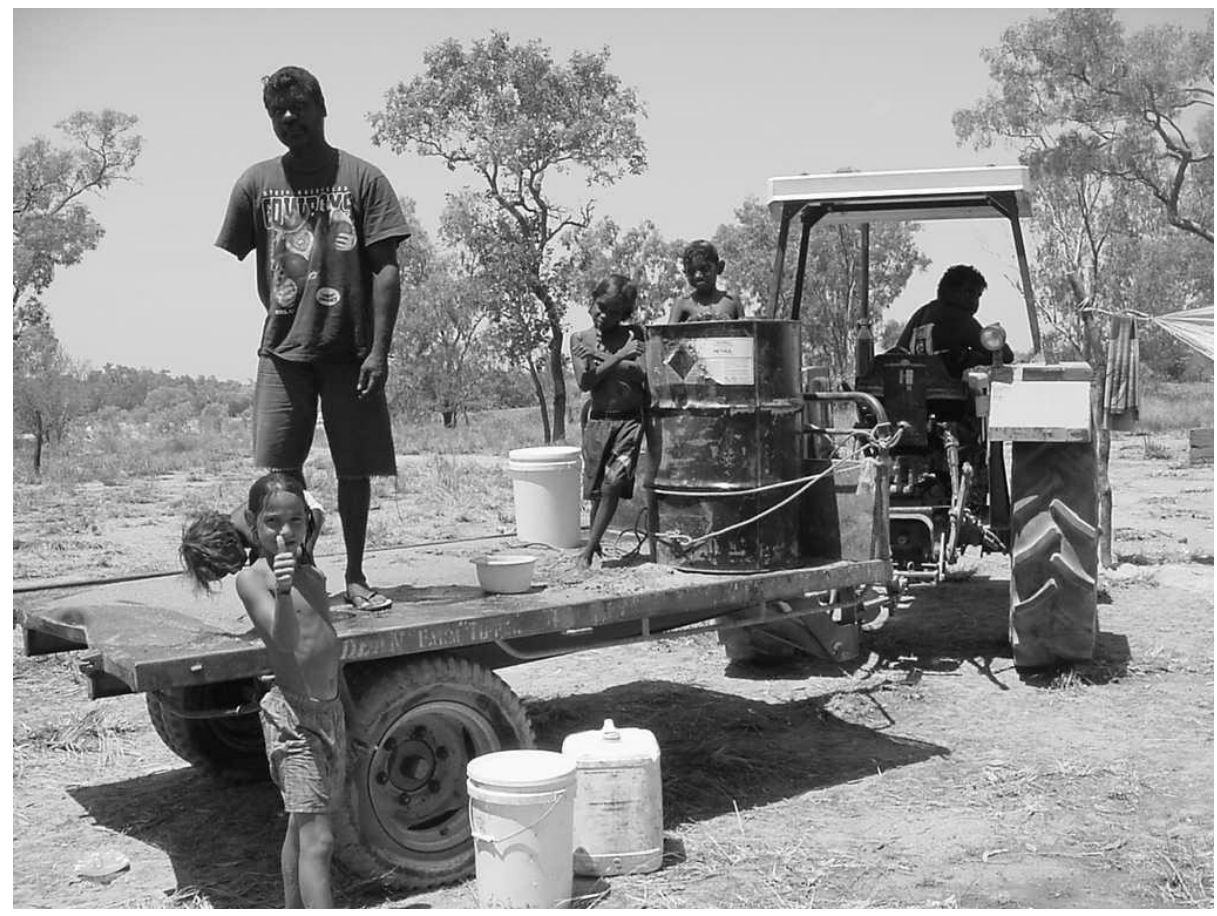

Figure 9.6 Carrying water and supplies to a dry season camp site Source: Kowanyama Collection

Figures 9.5 and 9.6 show aspects of a dry season camp site at I'ygow on the Mitchell River. This site, which is in Kunjen country, has had an outstation established on it since late 2002.

\section{Outstations}

Outstations are usually at locations where families have maintained their traditional links to their country in the occupation of temporary seasonal shelters or campsites over the years. Many of these sites now have more permanent 'shed' like structures on them which are set in concrete foundations and which have diesel generators to supply electrical power, a fresh water supply from rainwater tanks, toilet and shower facilities, and a communal cooking area. Each outstation usually has space for between 15 and 20 residents.

The majority of outstations consist of a cyclone-proof shed with a ground area of about $15 \mathrm{~m}^{2}$ and $30 \mathrm{~m}^{2}$, a generator, cooking area and water tank (Monaghan \& Taylor, 2003). Outstations usually commence at a dry season camp. Once a site is established, infrastructure support in the form of fencing and water supplies, and concrete foundations for more permanent 
residential structures are supplied as funds become available. The minimum infrastructure requirements for each site are stock-proof fencing, a shed for residence, water and solar energy supplies, and toilet and shower facilities. A sum of around $\$ 20,000$ has been allocated in the past for 'start up' costs for each site and Community Development Employment Project (CDEP) labour is used in their construction. The Federal Government has recently announced changes to CDEP parameters but as yet the effects of these changes are unknown. Longer-term aspirations are for the construction of permanent homes at some sites with the provision of between four and six houses depending on the number of families who live there (Monaghan, 2003a, 2003b). People at almost all outstations have aspirations to set up their own enterprises and exercise control over land use in their outstation areas. Prospective enterprises include small-scale cattle or aquaculture operations, or camps for tourists and recreational fishing. People spend as much time as possible on their outstation in their homeland country so as to escape the occasional rigors of township life and to enjoy the tranquillity of the bush (Monaghan, 2003a).

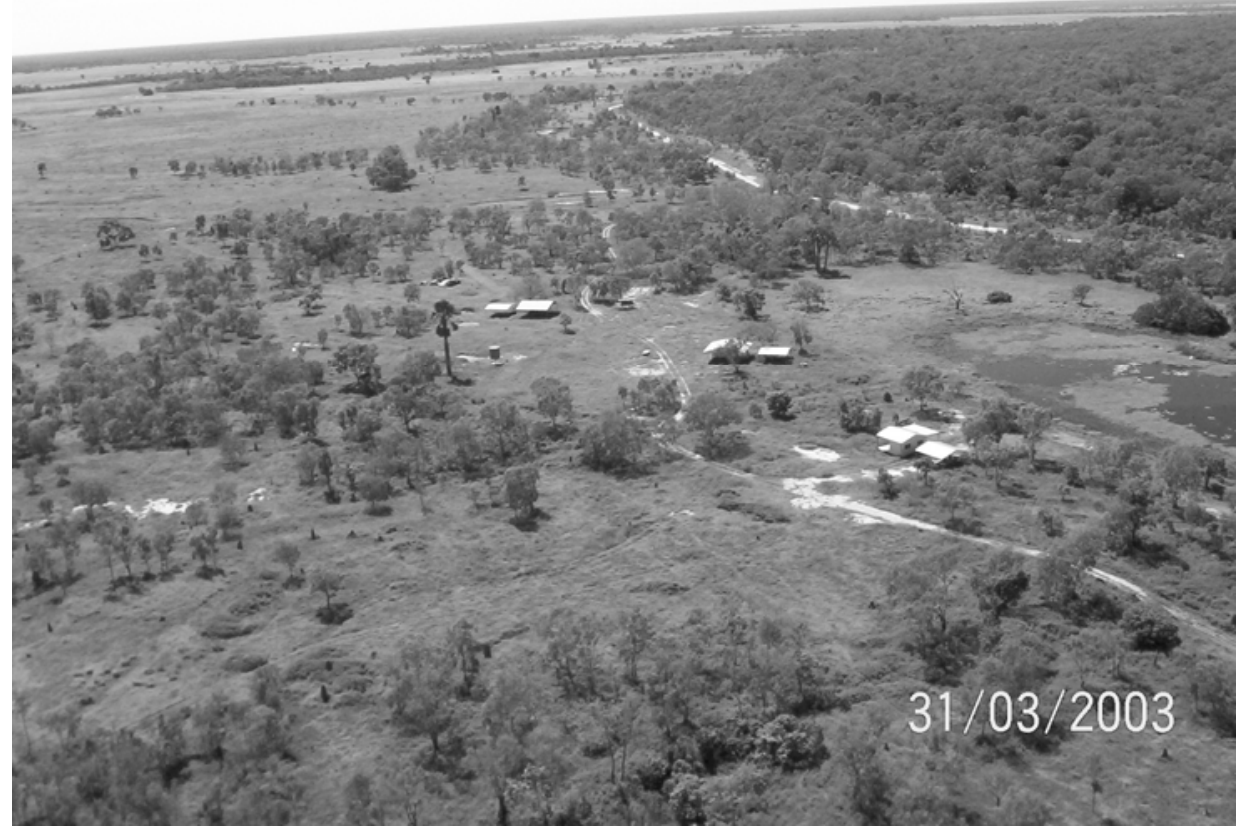

Figure 9.7 An outstation in Kokoberra country

Source: Kowanyama Collection 


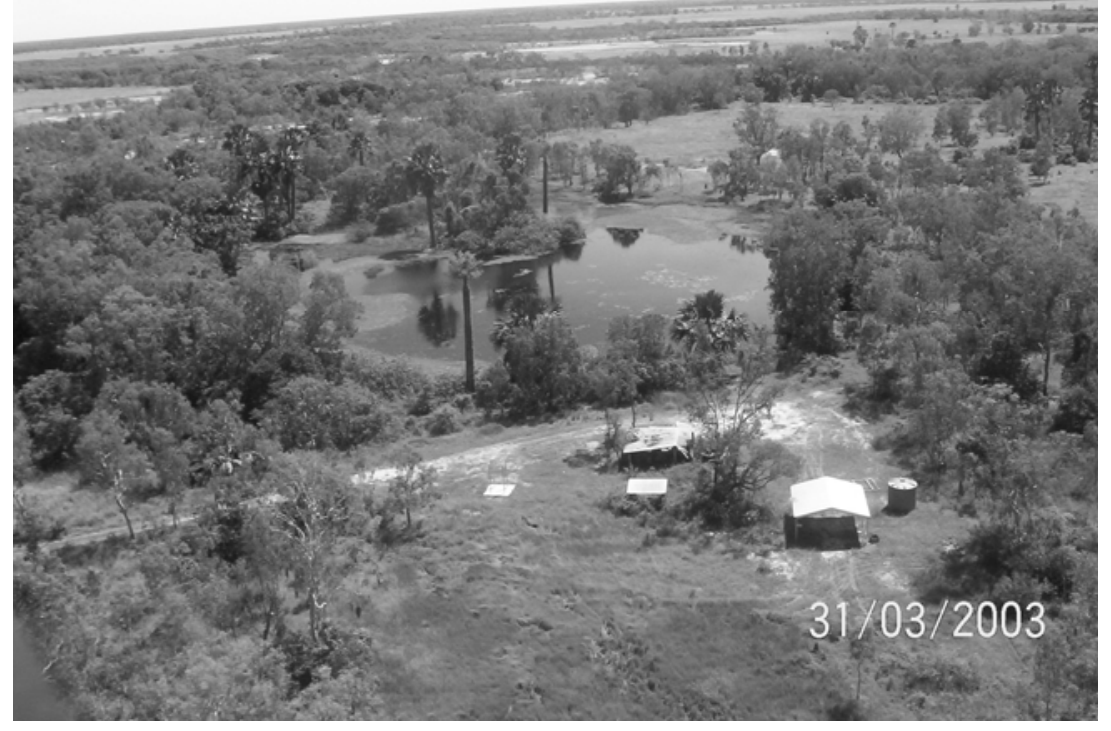

Figure 9.8 An outstation in Kokoberra/Yir Thangedl country Source: Kowanyama Collection

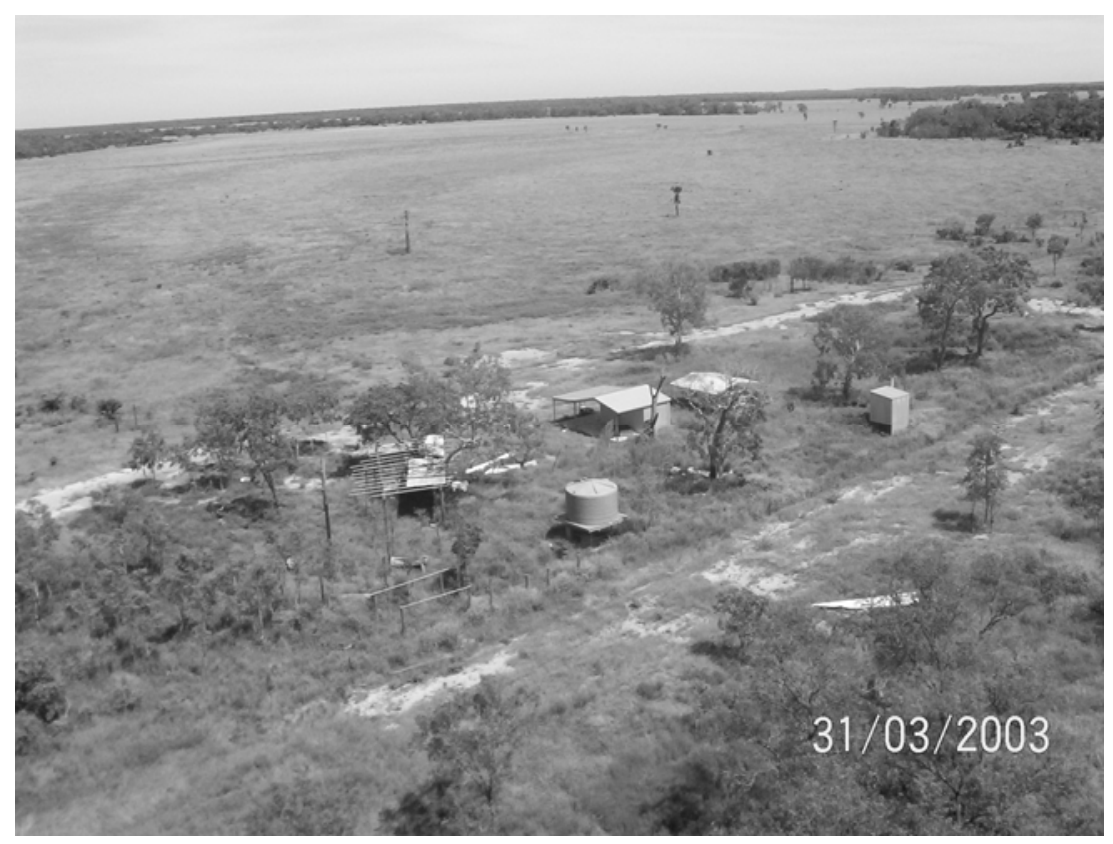

Figure 9.9 An outstation in Yir Thangedl country Source: Kowanyama Collection 


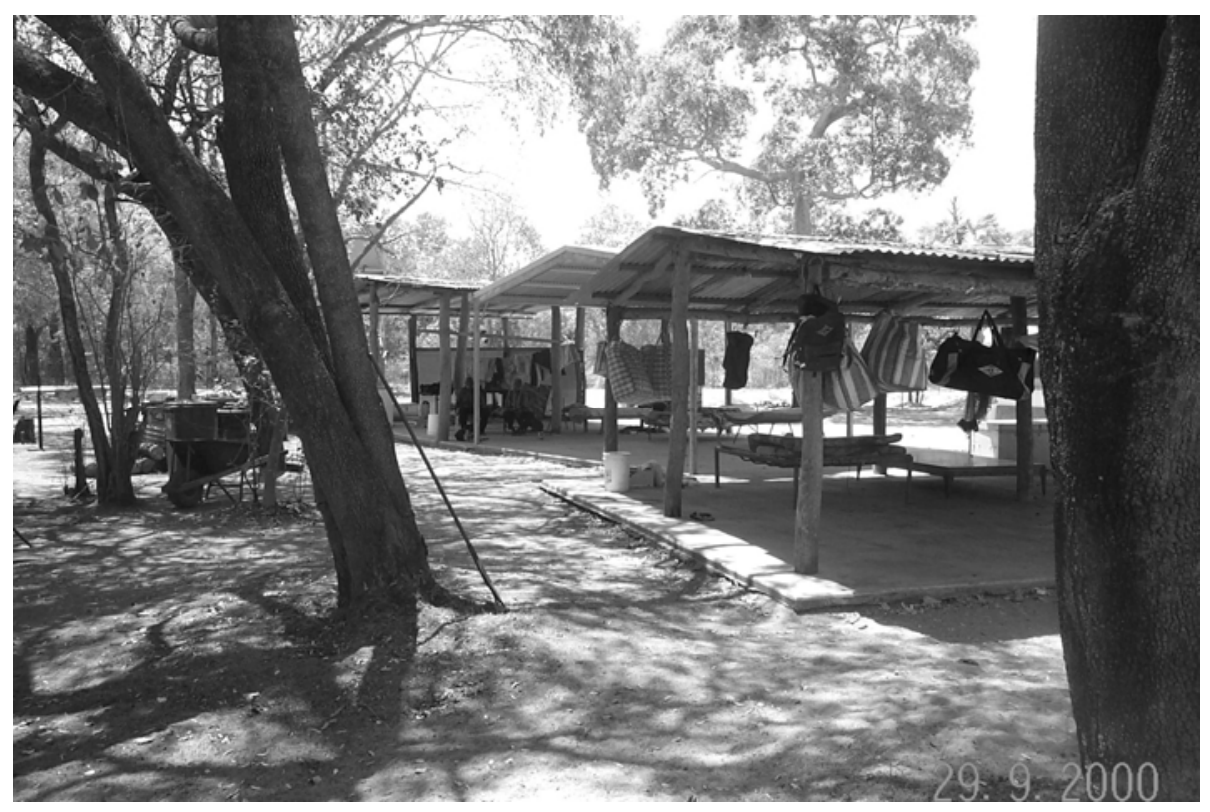

Figure 9.10 An outstation in Yir Thangedl/ Yir Yoront country Source: Kowanyama Collection

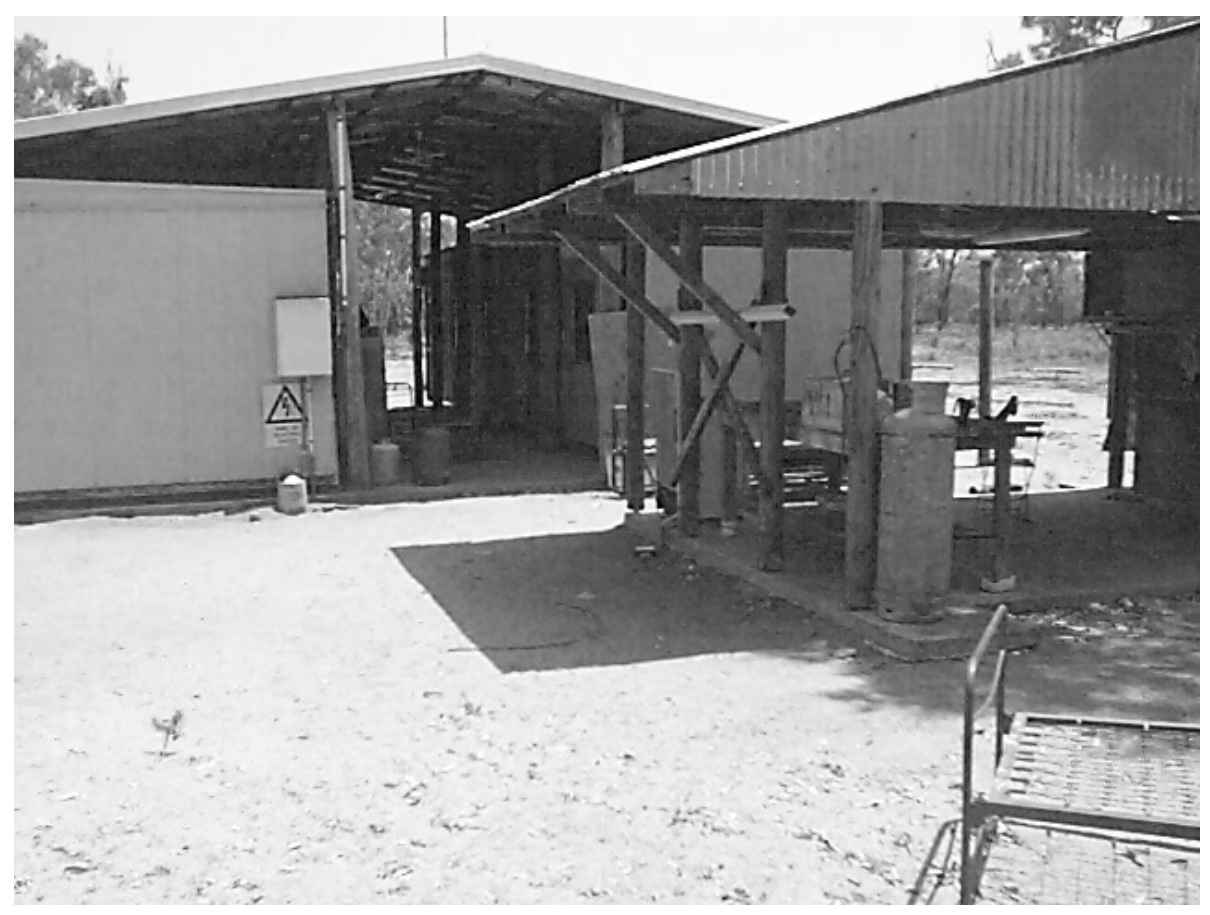

Figure 9.11 An outstation in Kuuk Thaayore country Source: Pormpuraaw Collection 


\section{Public and private space in peri-urban landscapes}

Decisions about where to locate outstations, and who should have access to them, are based on local criteria and negotiation between traditional owners and never involve any government agencies. Outstation groups are invariably identified either by the name of their leader, the surname of the dominant affiliate family, or by the name of the place or country where their homeland site is located. Affiliation, based on mother's country or father's country, underwrites the setting up of a homeland and the endorsement of all of the people with these affiliations is always sought before an outstation group proposes to establish a site. The group leader's immediate kin and those of any of their brothers and sisters, and the partners and offspring of any of their children are usually the people who will live at a homeland site. Otherwise, membership of an outstation group is by invitation. People do not put themselves forward and ask to join an outstation. If there is a sufficient number of uninvited people, who are proximally related in both a geographical sense to country, and in a social sense to family, then they may form their own homeland group and look for a site elsewhere within that region that is available to them (Monaghan, 2003a).

All outstations are private places and people are not allowed to visit them unless they are invited. In particular, they are exclusively Aboriginal spaces where people go to escape the rigors of township life, to assert their identity and connection to country, and to escape dependence on community health, education and police services. Each outstation is the centre of a tract of country that either reflects the traditional clan estate interests of its members or an area that has been negotiated with neighbouring outstation groups and other community members. Many people may have rights of access to country even though they are not members of any of the outstation groups within the country. These rights of access are usually based on secondary rights of association to country and natural resource use, which are transferred through kinship protocols (Sharp, 1937; Taylor, 1984).

The above processes mean that there are considerable variations in the accessibility of peri-urban landscapes, and their relative social permeability, which are also due to historical contingencies such as the nature of local mission and State Government administrations and geographical contingencies of distance from township, and wet and dry season access to traditional country (Monaghan, 2003a). For instance access to the Pormpuraaw landscape is heavily prescribed by traditional clan affiliations and outstations are discrete social and spatial entities that are maintained by various forms of social boundary defence (Cowlishaw, 1987) in public and private behaviour in community life (Monaghan \& Taylor, 2003; Monaghan, 2005). Even use of the Pormpuraaw hinterland is prescribed by clan and 
kinship affiliation. This is evident, for instance, in distinct household residency patterns in the township and in the wet season in the distribution of dinner camps and fishing parties along the seashore. A walk along the beach from the Chapman River to the Mungkan Creek when there is a wet season 'run' of salmon or black-tip shark in the near-shore waters of the Gulf of Carpentaria is an introduction to the cultural geography of western Cape York Peninsula. On the other hand, Kowanyama is a more permeable landscape in terms of patterns of social organisation, and patterns of outstation occupancy and natural resource use. This is particularly so in the Kowanyama hinterland where hunting and fishing are largely regarded as communal rights for Aboriginal people and for white 'staff' residents alike. Further away from the hinterland permission is always sought of an outstation group if any hunting or fishing trip is planned in their country, and this is invariably granted (Monaghan, 2003b).

The movements of any visitor to either Pormpuraaw or Kowanyama are always negotiated and planned before their arrival. People who arrive unannounced are accommodated if vacancies exist at designated camp sites; otherwise, they are directed away from the community. Kowanyama has a number of camps for recreational fishermen. Fishing permits are limited and demand for them is always high and never satisfied. The traditional owners of each camp site are consulted before the start of the fishing season on how many people may be allowed to fish there that year and a proportion of the fees that are received is paid into their outstation account and another proportion is allocated to the funding of aerial and boat surveillance of commercial fisheries in the Gulf of Carpentaria by community rangers (Monaghan 2003c). Tourist fishing camps have also been set up in the last three or four years at Pormpuraaw and some outstation groups there, as at Kowanyama, are looking at ways in which tourist-based enterprises may be included in future outstation planning. On the whole though, most people do not like to see strangers in their traditional country.

Both communities also have a herd of between 4,000 and 5,000 cattle which are run as part of open range operations and the low nutrient status of pastures and distance to market preclude any financial investment in infrastructure in the form of fencing, paddock control and artificial watering points or bores. Nonetheless, people at almost every outstation aspire to run their own herd of 'killers' or 'breeders' and negotiations between groups and the 'cattle company' in each community to exclude 'company' cattle from outstation country or to receive agistment fees for their use of country have increased in recent years. These negotiations can be quite terse with the cattle people regarding themselves as 'modernisers' and as managers of a community resource, and the outstation groups asserting their traditional authority over community lands. 
The community cattle operations are managed in the same way as any other pastoral enterprise in northern Australia and an important set of negotiations with outstation groups at the start of each dry season concerns the fire regime for the following year and in particular, when and by whom fires are going to be lit. These negotiations invariably require the reconciliation of two different systems of fire management, which are practiced by the cattle company and outstation groups respectively.

\section{Fire behaviour and fire risk in Aboriginal peri-urban landscapes}

Whilst some fires have their origin in lightning strikes, most fires on Cape York Peninsula are started deliberately as part of a land management regime of one kind or another. Controlled burning of the landscape has almost certainly been a feature of Aboriginal land use for many thousands of years and many of the traditional patterns of burning in terms of the location, timing and intensity of fires are repeated in present day control of pasture for cattle grazing.

The burning season starts almost immediately at the end of the 'wet' so that wet season growth and the more rank and unpalatable grasses can be cleared and cattle mustered or game such as wallaby driven out into the open for hunting. Early dry season fires tend to be low temperature and relatively small in extent. Burning continues through the dry season in order to promote the grouth of palatable pastures for cattle, and increases in intensity and extent in the late dry season as the surface and interstitial water reserves required to promote grass growth become depleted. In October/ November it can seem as if the whole landscape is either on fire or in some form of recovery from a fire. Indeed, a perusal of monthly fire-scar mapping between 2000 and 2003 by the Cape York Peninsula Development Association (CYPDA, 2003) shows that there are hardly any areas of the Peninsula that are not burnt at some time.

Fire is also a phenomenon which is part of Aboriginal cosmology and is a motif of clan identity for some people in western Cape York Peninsula whereby they are required to perform duties that involve the creation and maintenance of fire in the landscape so that its contributory role to Aboriginal belief systems and the existence of the physical and social world is ensured. Traditionally, the failure to perform such duties would threaten the entire physical and social world and the cosmology or 'stories' that describe and underpin the creation and continuity of the universe (Sharp, 1937). Fire is linked through creation stories to other elements of the physical world and the narrative must be continuously maintained in story-telling and in actions in the landscape; for instance, members of the Grass Clan have important duties to perform in ritual aspects of the use of fire in land management as 
grass is both destroyed and created by fire. The performance of these duties is an affirmation of personal identity and of responsibility to the rest of the community. 'Smoking the country' is a ritual act of purification of the landscape which is widely practiced throughout the western Peninsula, usually following the ending of a mortuary ban which is a period when areas of the landscape are closed following the death of a person affiliated to that country. This ceremony is very localised and performed at the place of strongest totem affiliation or sentimental attachment for the deceased. Mortuary bans often disrupt the operations of the community cattle company and also the holiday plans of visitors to the community.

Traditional owners monitor the physical appearance of their country and if, because of the growth of understorey vegetation ('rubbish'), they feel that it has not been adequately burned then they will perform that duty. Some traditional owners who have been away from their country for a long time will light a fire anyway, probably to demonstrate their ownership and their duties for the custodianship of that land. Such fires tend to be small in extent as, particularly later on in the dry season, ground cover can be very sparse and there is often little combustible material around. The large hot fires of this time of the year have to be started by incendiary devices that contain diesel or petrol. In summary, fire setting can be an expression of identity, of control of the physical, mythical and social world, as well as a land management technique.

In a Natural Disaster Risk Mitigation study for the Pormpuraaw community (Monaghan \& Taylor, 2003), local people regarded uncontrolled fire as the main natural hazard in the dry season landscape. In fact, uncontrolled bushfire was unequivocally identified as a greater natural hazard than cyclones or extreme wet season floods. Fires can break out suddenly and extend over large areas very quickly. In this sense, they are the least predictable of all natural hazards. The reason for their unpredictability, which was identified unanimously by all of the outstation and cattle people who were interviewed in the study, is that the main cause of uncontrolled fire is negligence by people who drop matches or poorly extinguished cigarettes. Most outstation residents expect a bushfire to come in close proximity to their property at least once a year. Strathgordon, an Aboriginal-owned pastoral property about 60 kilometres from Pormpuraaw, experienced a bushfire in August 1999 that came close to the homestead and which could only be extinguished with the help of neighbouring pastoralists. The dry season is also the time of year when most tourists visit the community. At present, the activities and camping locations of tourists are largely unregulated though the community has established a Ranger service recently. The supervision of tourist activities is one of their roles. Camping locations at Kowanyama are more closely supervised and Pormpuraaw is 
obtaining advice from community rangers there on procedures for the surveillance of tourists.

One of the most unappreciated properties of western Peninsula landscapes is the number of Aboriginal people who are camped in them at any time during the dry season and in particular at weekends. The bush, both within periurban areas and beyond in more remote areas, is literally alive with people, who move around either on foot or in four-wheel drive vehicles. It is hard to avoid people or indications of the presence of people such as a recently vacated dinner camp. Current scientific opinion is that most of the western Peninsula is a 'wilderness' (Abrahams, et al., 1996) with exceptional nature and remoteness qualities. This is quite literally an anti-social perception of landscapes in the region as they are populated by highly mobile, and in the context of bush hazards, highly vulnerable people. A few years ago, a search was conducted by the Australian Army for an area where live ammunition' exercises might be undertaken in the western and central Peninsula. The search was abandoned as it became clear that it was not even possible to fire a handgun at any place or in any direction without the risk of endangering lives.

When people set up camp, vegetation is cleared on a large area of ground to create a firebreak and then they collect fuel and light a fire. Fires are continuously tended and when the camp moves on, fires are extinguished with earth and water and the remnants buried. Fire risk reduction is an abiding principle of bush life for people on the Peninsula.

Despite the unpredictability of bushfires, Pormpuraaw people feel that they can manage and remove the risk of uncontrolled bushfires (Monaghan \& Taylor, 2003). The fire regimes practiced by pastoralists, whether European or Aboriginal; rely on any area of the landscape only being burnt once, and twice in exceptional circumstances, in any dry season. Good fire management regimes not only promote fodder for cattle but they also remove fuel loads for future fires. Outstation organisers and cattle workers in Pormpuraaw and Kowanyama continually remind the rest of the community that only they should light fires in the bush. Planning meetings have been held at the start of the dry season in Kowanyama to formally plan each year's fire regime and monthly satellite images and fire-scar mapping are inspected by traditional owners and cattle company workers to monitor the extent of burning in the landscape.

The greatest risks of a catastrophic bushfire are around outstation sites as they often have generators and stores of diesel fuel on site. In terms of risk reduction it is clear that fencing around sites; well-defined firebreaks and little vegetation or vegetation debris within the living area at each site are the 
best ways of safeguarding a site. During visits to outstation sites in November 2001 it was clear that those sites which had been identified as the most fire-prone were unfenced and had a lot of undergrowth and dry vegetation debris within their vicinity and were clearly at greater risk from late dry season wild fires (Monaghan \& Taylor, 2003).

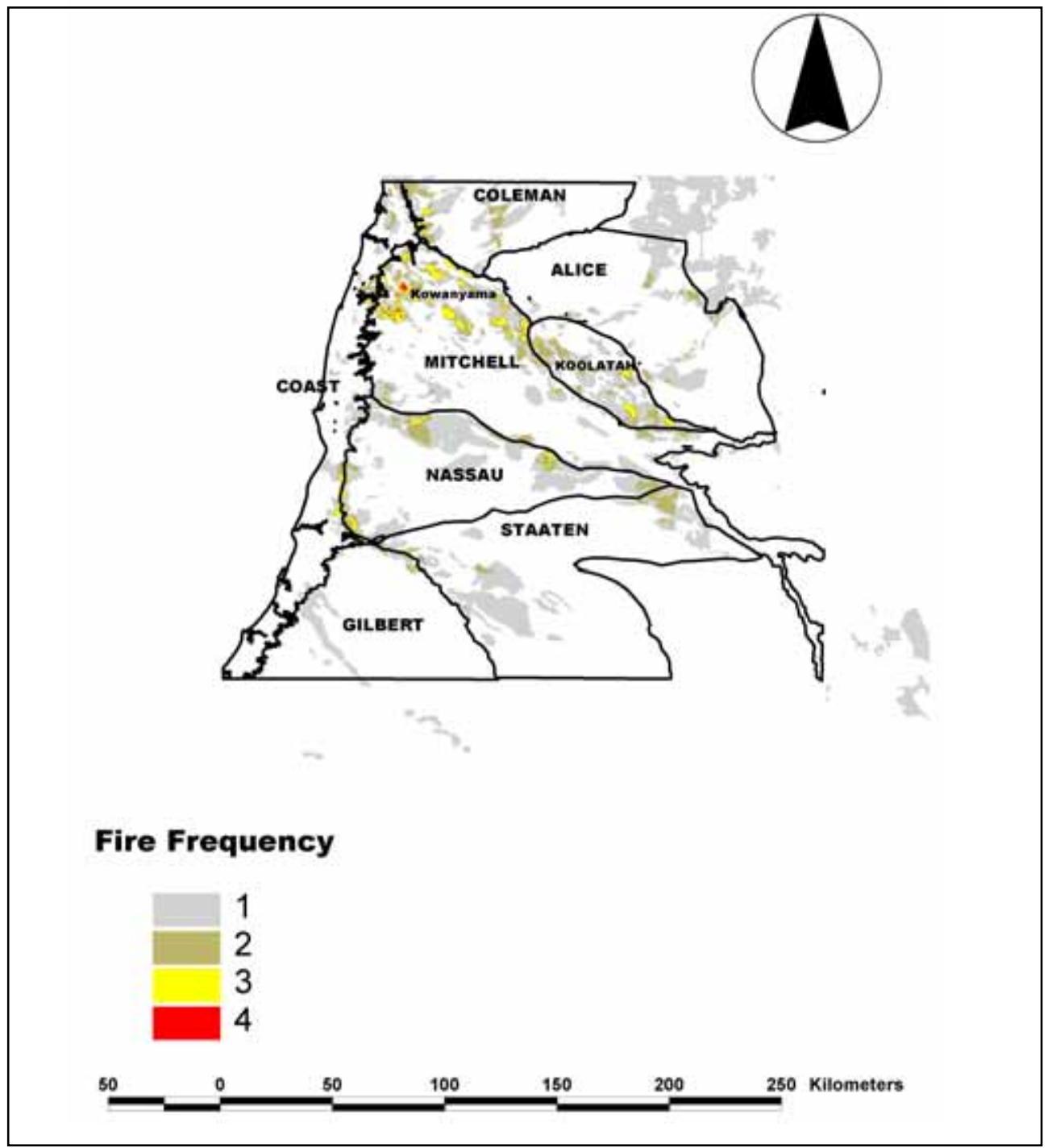

Figure 9.12 Early dry season fire frequency 1999- 2002

Source: Monaghan, 2005 


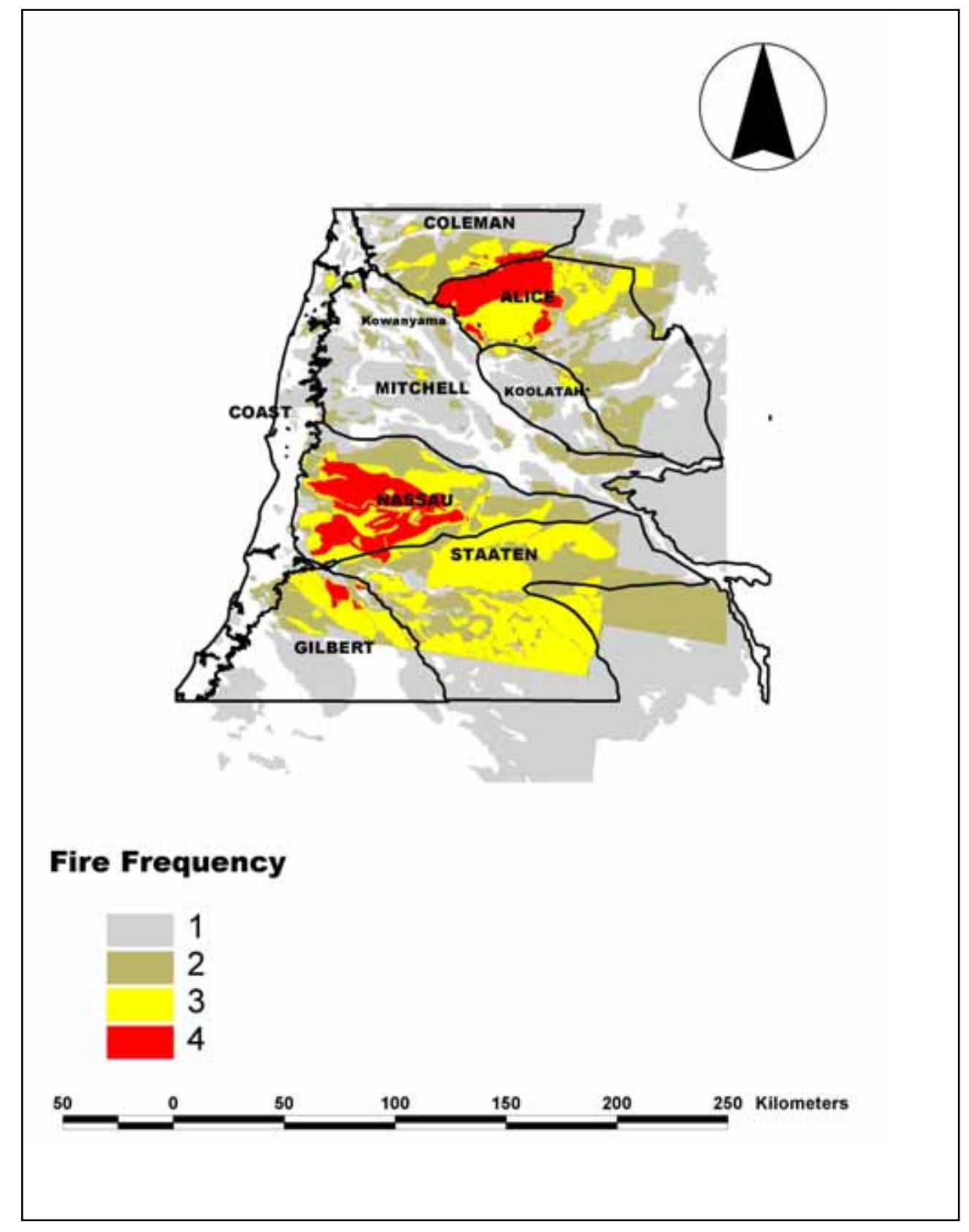

Figure 9.13 Late dry season fire frequency 1999- 2002

Source: Monaghan, 2005 


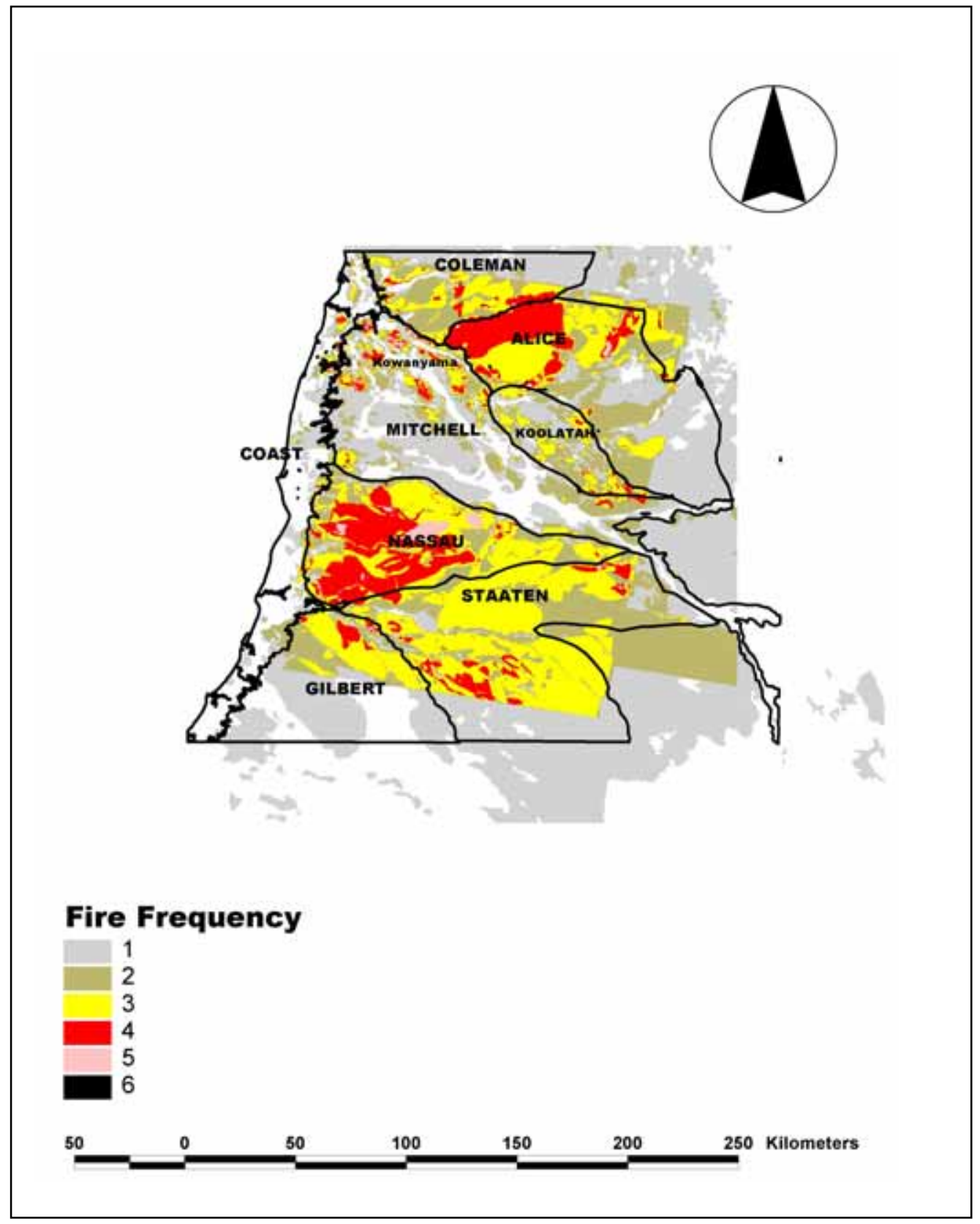

Figure 9.14 Entire dry season fire frequency 1999- 2002

Source: Monaghan 2005 


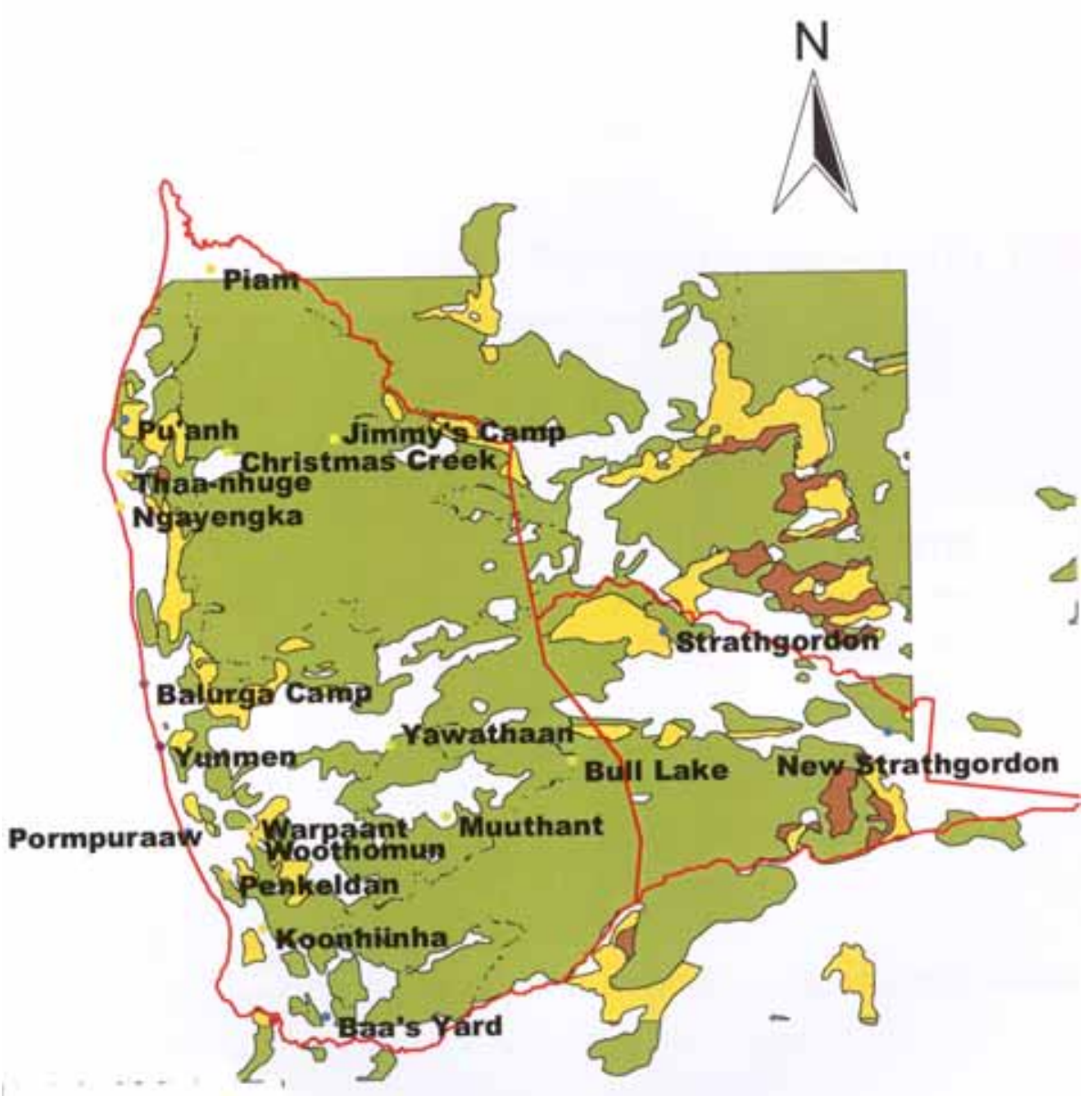

Fire Frequency

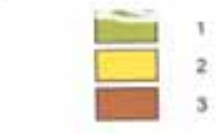

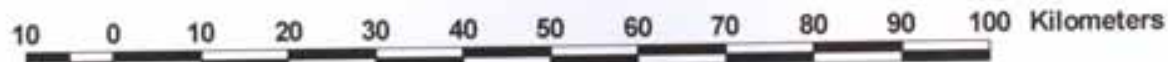

Figure 9.15 Outstation sites and fire frequency in 2001 in the Pormpuraaw DOGIT and Strathgordon pastoral property

Source: composite of CYPDA J une, J uly, September and October 2001 fire-scar 


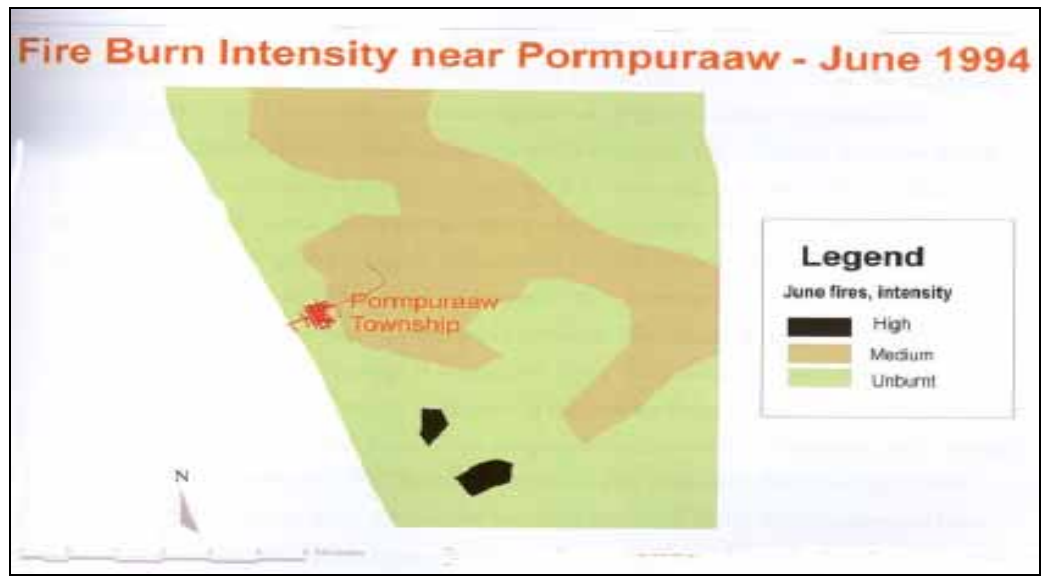

Figure 9.16 Fire scars in the vicinity of the Pormpuraaw township J une 1994 Source: Anyango, 1997

Table 9.1 Bushfire risk treatment options in Pormpuraaw Natural Disaster Risk Mitigation Plan (Monaghan \& Taylor, 2003)

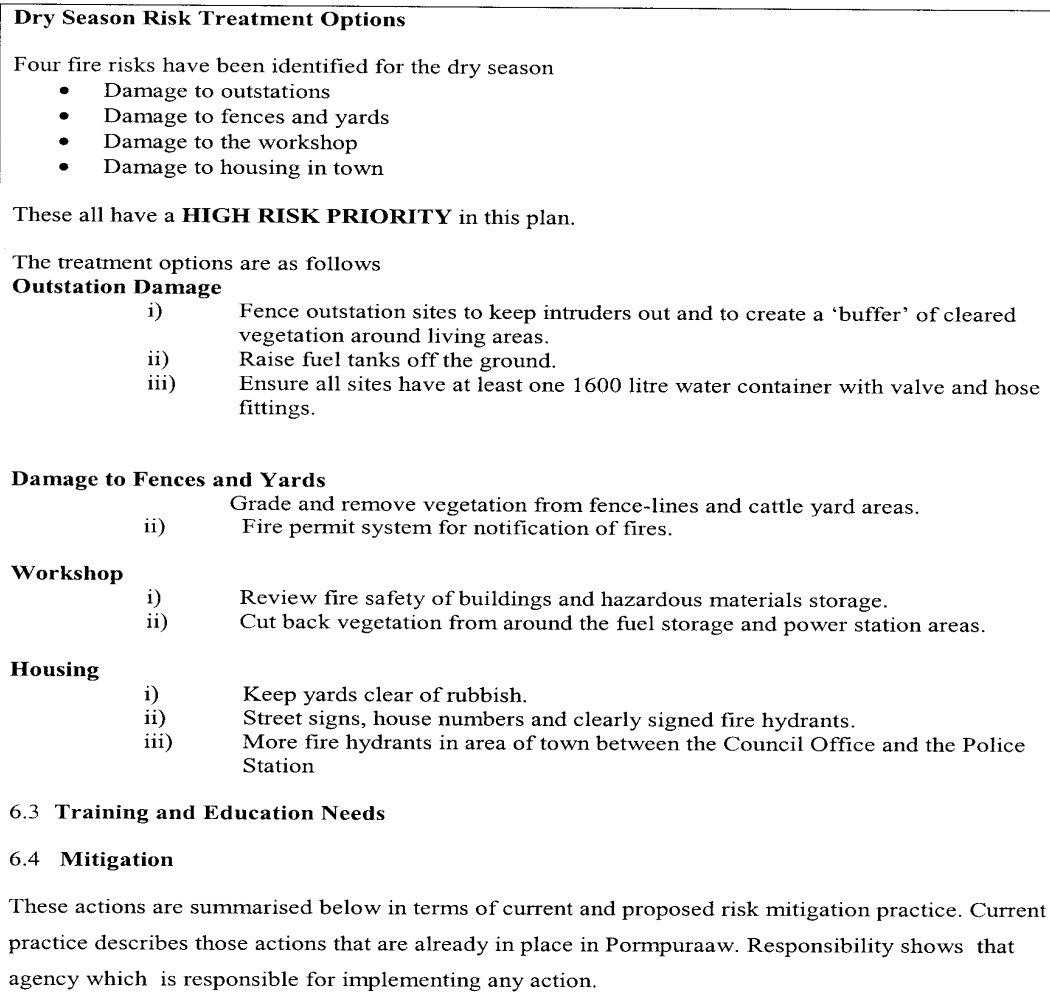

iii) More fire hydrants in area of town between the Council Office and the Police Station

6.3 Training and Education Needs

6.4 Mitigation

These actions are summarised below in terms of current and proposed risk mitigation practice. Current practice describes those actions that are already in place in Pormpuraaw. Responsibility shows that agency which is responsible for implementing any action. 
Table 9.2 Fire management in Kowanyama Natural Resource Management Plan (Norris, 2003)

\section{CURRENT SITUATION}

- Many areas are burnt every year.

- Burning is a widespread practice to improve pasture in either the early or late wet dry season

\section{STATUTORY REQUIREMENTS}

- Permits are required from the Fire Warden (Bob Crapp) for fires in the vicinity of town.

- Local fire bans were enforced during Government administration time at Kowanyama (1960's to 1980’s).

\section{COMMUNITY VIEWS ON FIRE MANAGEMENT}

- Protect people and property from fire damage--create fire breaks systematically (e.g. around the community and around homelands).

- Minimise spread of fires across Kowanyama's boundaries, either from Kowanyama onto our neighbours, or from our neighbours onto Kowanyama - create boundary fire breaks.

- Plan burning of Kowanyama country systematically each year.

- Learn more about the long-term effects that our current burning is having on our country.

- Meet our current legal requirements for prevention and control of fire at Kowanyama.

\section{CURRENT POLICIES AND PRACTICES}

- Burning is important for looking after country.

- There are times during the year when some places shouldn't be burnt, even if they could be. Some people light fires when they should not.

\section{Reasons to burn}

\section{Burning by Cattle Company}

- prepare the ground for new grass, ready for the wet season; rejuvenate the country

- clear scrub for fence lines

- burn out cattle ticks

Burning by Traditional Owners

- clean up/rejuvenate country, get rid of old wet-season grass, make way for new grass for wallabies, cattle etc.

- improve access to country, fire is an important tool for hunting and gathering (some areas you can't get into or through without burning) e.g. collecting turtles in swamps is easier after a fire.

- make places safe e.g. burn out snakes

- communicate using fire and smoke - white smoke $=$ all is well; black smoke $=$ come and help.

- burning around homeland areas to create fire breaks

- burning for traditional reasons:

- some people have fire or grass as their story, and it is important for them to burn their country 
- ceremonial burning, when people 'meet the place' after funerals and closures of country

\section{Other burning}

- burning for weed control (this is currently a side-benefit of burning, it is not yet done systematically or deliberately for weed control)

\section{Reasons not to burn-risks of burning}

- can ruin cattle pasture at the wrong time of year (early fires that deplete cattle feed for later in the dry season create a problem for the cattle company)

- badly timed fires can disrupt cattle company work during mustering operations

- can damage property and injure people

- can damage wildlife and wildlife habitat (e.g. geese egg/nesting areas)

\section{Sources of fires-who lights them?}

- Most fires are lit by Traditional Owners or the Cattle Company.

- Fires for improving cattle feed are generally lit by the Cattle Company (although Traditional Owners also burn to improve grass).

- Fires for improving access to country are generally lit by Traditional owners (although Cattle Company also burns for access).

- Tourists and neighbours sometimes start fires.

- Some fires are accidental (lightning strikes, camp fires getting away, cigarettes out the window).

\section{INTERIM STRATEGIES FOR FIRE MANAGEMENT}

\section{Activity area}

\section{Interim Strategies}

\section{Planning}

Mapping could be invited to be involved.
- Have annual (or other regular) meetings so that Traditional Owners, Cattle Company and Land Office can discuss the timing and location of fires for the coming season. This should happen late in the wet season or early in the dry season when the roads open (e.g. after easter). Our immediate neighbours

- Homeland groups to plan their firebreak burning each year.

- Land Office to keep receiving and monitoring satellite pictures, to watch what fire is actually doing to Kowanyama country, so that we can understand fire better

- Land Office to contact the DNR fire project team in Mareeba to thank them for the satellite data and assure them that we want to keep receiving the data.

- Land Office to confirm current legal requirements for fire permits at Kowanyama (local SES coordinator has details) and communicate these widely to the community. 


\section{Fire risk reduction}

Table 9.1 provides a summary of the risk treatments that were developed, on the basis of current community infrastructure and human capacity, for coping with bushfires in the Pormpuraaw study (Monaghan \& Taylor, 2003).

The main recommended on-site treatments for outstations include the following:

- fencing of outstations and the creation of a 'buffer' area of bare ground around living areas;

- $\quad$ raise fuel tanks off the ground onto supporting stands; and

- $\quad$ ensure an on-site water supply.

It is clear from interviews, historical fire incidents and from fieldwork that those outstations that are most at risk from fire are either unfenced or have dense vegetation around them. At the level of regional infrastructure, anecdotal reports on the western Peninsula and fire scar maps created from satellite imagery (for instance Figure 9.15) show that there is a clear concordance between roads and fence-lines and the outbreak of bushfires, either from careless disposal of matches or cigarette butts or from arson. As in the rest of Australia, arson is a potential problem and clearly as new outstations are introduced then the potential for new access roads arise and hence the overall fire risk of the landscape that is traversed by them increases. Fire came within 200 metres of every outstation at Pormpuraaw on at least one occasion in the 2001 dry season, and to within 100 metres of four of these sites.

Figures 9.12 to 9.14 show fire frequency in the Kowanyama region against a background of the major physical and cultural landscape units that have been identified in the region by Kowanyama people as part of a community natural resource mapping program (Monaghan, 2005). These maps show fire frequency between 1999 and 2002 and illustrate, at a regional scale, a stable pattern of seasonal burning with each landscape unit encompassing a fairly distinct 'signature' in terms of fire frequency and fire scar size. This pattern suggests that fire regimes are as much a product of their physical environment as any prevailing land management regimes. There are some exceptions to this pattern in that late dry season burning to the north-east of Kowanyama (see Figure 9.13) is characteristic of a particular pastoral property These outbreaks have led the Kowanyama community to take precautionary measures in clearing firebreaks on the community boundary. Late dry season fires are invariably more extensive in area and in intensity than early dry season fires. Figure 9.16 shows the distribution of fire scars around the Pormpuraaw township in J une 1994 (Anyango, 1997). 
The occurrence of fires close to town is quite frequent and is mitigated by a fire break that is cleared around the town each year. Fires also come in quite close to Kowanyama and the Magnificent and Gooseberry Creeks, which always contain water, provide natural buffers to the spread of wildfire, also the country that is closest to the township is burnt and grazed early in the dry season so that later dry season fuel loads are never too high.

Table 9.2 is an extract from the Kowanyama natural resource management plan (Norris, 2003) and provides a summary of the main points about community fire management in Kowanyama. The creation of firebreaks around outstations ('homelands' in Kowanyama) are part of annual fire planning with the community cattle company.

The Pormpuraaw study also identified the following issues as germane to effective natural hazard risk management:

- The difference in perceptions of risk from natural hazards between local people and the 'staff' population - local people are more accepting of these risks and of their ability, and the capacity of the Council, the police and the SES to deal with them;

- The maintenance of risk standards in the future planning of community housing, infrastructure and land use;

- The absence of a rate revenue base and the reliance on external funding for Council operations;

- $\quad$ Training and equipping of SES volunteers and community rangers (Monaghan \& Taylor, 2003).

The main issues in bushfire risk management planning in remote Aboriginal communities revolve around the socio-political context of each community in terms of staff-community relations and local Indigenous systems of governance.

\section{Socio-political considerations in fire risk management}

Remote Aboriginal communities are characterised demographically by a large, permanently resident Indigenous population with a more transient population of service deliverers who are mainly European Australians. There are also two separate systems of governance in DOGIT communities in Queensland in a locally elected community council which fulfils the role of a local authority as is found in communities elsewhere in rural Queensland. The other form of government is in local polities which consist of tribe and clan affiliations that are based on traditional governance protocols and more recently in the 1990s and early 2000s in homeland or outstation groups who are the land-holders of traditional country. 
With reference to Pormpuraaw and Kowanyama, this section of the chapter highlights the socio-political differences that exist between Aboriginal communities and the implications for regional-scale risk management strategies in northern Australia.

\section{Community demography and service delivery}

Pormpuraaw currently has a population of about 633 people (ABS, 2002), 559 of whom are Aboriginal people who are long term residents, the majority of the remainder are white 'staff' residents who tend to remain in the community for between two and five years. Kowanyama has a population of about 1200 people and a staff population of comparable size. As was highlighted in the previous section of this chapter, the attitude of these two populations to the management of bushfire and other natural hazard risks can differ quite markedly.

Staff are individuals and their families who have positions in Council administration or its agencies, or in the State Government service sector. Most staff are temporary residents, mainly non-Indigenous, and employed on a term contract. They are generally highly skilled people who work as police, teachers, nurses, clerks, accountants, and managers or tradesmen. Those employed in the State Government positions rarely stay for longer than two years and many are in the community under financial inducement or with the promise of a 'fast track' posting to a more a desirable location or a more senior position. Those people who work for the Council tend to stay longer. In time, all staff members move on and on the whole the staff population is a transient and changing one. About $20 \%$ of the staff population at any time are single persons. Married couples with no children or with grown-up families make up more than $50 \%$ of the staff population. Those staff families who do have children of school age send them away to boarding school. It is common for both married partners to find employment in the community (Monaghan \& Taylor, 2003). A similarly constituted staff population is also present in Kowanyama.

Turnover in the staff population can lead to swings in 'corporate' morale in the various service centres in a community and individual people can have great influence, if they choose to exercise it, in community life. More so than Pormpuraaw, Kowanyama is characterised by a relatively stable staff population who tend to remain in the community for a longer time. On the whole, western Peninsula communities have a welfare economy and local people have a low material standard of living by mainstream Australian standards. They are poorly equipped to deal with the kind of investment in supplies and household preparations that are normally undertaken by a family to prepare for a natural disaster and have great reliance on the 
Community Council and Federal and State government agencies for sustaining daily life. Most of the employed population work on schemes funded by the Commonwealth government's CDEP scheme that supports projects that provide or aim to improve infrastructure and social services in the community. Many of these projects in fact provide essential community services. The wages that people receive are the equivalent of social security or unemployment benefit payments (Monaghan \& Taylor, 2003).

Good relations exist between staff and permanently resident populations in both Pormpuraaw and Kowanyama. New staff members are often introduced into local families and many are assigned fictive relationships within local kinship networks which enable them to gain an insight into local systems of social organisation and modes of community governance. It is impossible for many staff to work effectively without this understanding of how local society works and those who acquire this knowledge and familiarity with community life are often those who are less susceptible to 'burn out'. Council and other service staff are invariably busy people who are also faced with the pressures of being expected by government to deliver mainstream standards of service in contexts where under-funding, lack of peer support and remoteness and isolation often make such expectations unrealistic. Local people are often supportive of staff who would otherwise find it difficult to cope and help them to 'cut corners' so that their work may be done, mainstream goals achieved (though not necessarily in the way that government policy demands) and their morale sustained.

The Pormpuraaw study identified a tendency for local people to rely on service deliverers, such as emergency services personnel; this is part of a wider pattern of dependencies that arise out of local economies that are overwhelmingly welfare-based. In another sense this dependency can be viewed as an active rather than a passive phenomenon, which is symptomatic of the way that local-mainstream relations are conducted by Aboriginal people so that their distinctive cultural and social identities are maintained. Australian government attempts to assimilate Aboriginal people into mainstream lifestyles have been described in terms of 'social' and 'material' technologies (Chase, 1980; Smith, 2000). For the purposes of this chapter, social technologies may be regarded as paradigmatic changes by government in their management of Aboriginal affairs such as church administrations, DOGIT tenure and the introduction of regional scale Aboriginal government in the Aboriginal and Torres Strait Islander Commission (ATSIC) and Land Councils in the early 1990s; and now in the early 2000s the transformation of DOGIT administrations into shire councils, just like those that exist elsewhere in rural Queensland. Material technologies are those instruments such as housing and infrastructure, 
health and education services, or telecommunications which are the expected agents of social change within any prevailing paradigm (Monaghan, 2005).

To briefly summarise the influence of social and material technologies on mainstream-Aboriginal relations, the Aboriginal response to institutional change through social technology is to 'underground' the main cultural elements of their society and to accommodate social change within their own systems of social organisation. An example of the latter is in the fictive relationships that are assigned to staff people so as to place them within the local Aboriginal social universe. 'Undergrounding' refers to the oblique view of the Aboriginal domain and of core decision-making by people about their affairs outside of the community council that is often only partially visible on initial visits to a community. Political activity is conducted within the network of locally evolved traditional and historically based protocols that determine social relations within any particular community and is exclusively Aboriginal.

\begin{abstract}
Aboriginal decision-making and relative autonomy or domains of relative autonomy tend to be concentrated in areas conceived of by outside interests largely as private affairs not as part of the public domain, and these are areas such as entertainment, gambling, sport and religion or ceremonies or whatever. In reality, though, these areas may be the very ones that contain focal and basic stages on which Aboriginal public, political and economic life is lived out and in which they exercise what to them may be quite critical areas of relatively autonomous decision-making. In other words, they are not a side show, they might be core activities for people, and core activities for whole communities (Sutton, 1990; cited in Rowse, 1992, p. 20).
\end{abstract}

In terms of material technology, services such as welfare and pension payments and household and neighbourhood organisation, which have arisen from town planning, are received into local modes of social reproduction such as kinship and reciprocity relationships (Monaghan, 2005).

"Material practice is embedded in and is the articulator or mediator of social meaning" (Smith, 2000, p. 429). For instance, natural resource management practice by community rangers in Kowanyama and Pormpuraaw includes the use of remote sensing and computer satellite images and global positioning systems as well as control of the environmental and mythical properties of the landscape from those special places, poison places or increase sites, where the ritual knowledge and belief systems that are associated with natural resource management are located. There is no sense of any traditional or modern dichotomies in management 
practice by rangers; instead, all of the technologies and techniques that are used by them are regarded as one integral suite of management tools (Monaghan; 2001, 2005). Community rangers are also at a nexus between the delivery of mainstream services or the enforcement of mainstream regulations and local customary practice, and on the whole they try not to confront the authority of traditional owners who may accuse them of acting like a white fella', or who may invoke clan and kinship affiliations to question the authority under which a ranger is working in any situation. The latter criticisms are strongest in any issue to do with land management, more so in homeland country. Also, such criticisms are strongest in issues, such as bushfire risk management, where the feeling is that intervention or support from outside is not required because most people feel that they deal with the issue adequately; and when such opinions are expressed then this is often true.

The successful introduction of mainstream management practices into local communities, whether they are Aboriginal or otherwise, requires a period of time in which they are allowed to embed themselves into local practice. Moreover, the uptake of mainstream management practices is even more successful if people are made aware of their availability and then left to make their own decisions on their utility; and, providing a grant or unsolicited financial aid is absolutely no guarantee of success.

Homelands are becoming more autonomous political and land-holding entities in the early 2000s in Cape York Peninsula and native title rights and forthcoming legal changes in the way that Aboriginal community councils are constituted are probably going to make them the authority and operational unit in the management of Aboriginal peri-urban landscapes within the foreseeable future.

\section{Political considerations in the management of Aboriginal peri- urban landscapes}

As stated earlier in this chapter, there are two forms of government in remote Aboriginal communities in the locally elected council and in the 'Aboriginal domain' of tribe, clan or kinship affiliations. These polities tend to look after the affairs of the township and the landscape respectively.

Councils comprise seven members and are elected every three years. Each council has a chair elected from their membership and a Council Clerk or Chief Executive Officer is responsible to Council for the administration of the community. Membership of the council in Pormpuraaw is usually representative of the 'tribe' or language groups who live there. The township is divided into two neighbourhoods based on linguistic affiliations. There are 
speakers of Wik dialects in the northern neighbourhood - 'Mungkan side' and speakers of Kuuk Thaayore on the southern - 'Thaayore side'. There are also Yir Yoront speakers on Thaayore side and speakers of non-Wik dialects such as Bakanh on Mungkan side. The distinctions between the two neighbourhoods are based on language and clan estate affiliations and there is little overlap between people in these groups in daily life. The composition of the council at Kowanyama is more eclectic and reflects a larger and more heterogeneous population whose traditional country may be found over a wide area of the southern and western Peninsula and the northern Gulf country.

Pormpuraaw (formerly the Edward River Mission) was the last Aboriginal mission to be established in Queensland in 1939 whereas Kowanyama (formerly the Mitchell River Mission) was established in 1903. There are clear differences between the two communities in their colonial histories and in their respective geographies in the way that State-assigned reserve boundaries coincided with the underlying political geography of pre-contact Aboriginal tribes and language groups at the time of their establishment. For instance, Pormpuraaw traditional owners have lineages based on descent to the mythical figures who are emblems of clan identity (Taylor, 1984) and those in Kowanyama mainly have a cognatic system based on connection to apical ancestors who are identified by the name of those male ancestors who were alive at around the time of the establishment of the Mitchell River Mission (Taylor, 1999). Despite the post-colonial changes that have occurred in social organisation, almost all patterns of social behaviour and land management practice in both communities find parallels in those recorded by ethnographers in the early years of the twentieth century (McConnel, 1931; Sharp, 1937; Roth, 1907).

The most visible form of Aboriginal polity in community life and the one that has the greatest authority in land management is the homeland or outstation group.

The role of the leader and their capacity as a broker in reconciling secular and traditional interests in their homeland country and in negotiating for homeland services with the Community Council or with government agencies is crucial to the success of a homeland group. Three or four homeland groups may combine to form a 'mutual society' of support for their members. These societies prioritise homeland development plans between themselves and make plans for enterprises, such as cattle grazing, aquaculture or fish ranching, or tourist fishing camps to sustain their homelands in the future. They occupy geographically contiguous areas and share strong clan associations and also have the strongest corporate identities in 
community life. Their 'focal' leaders, of which there are four or five in Kowanyama and in Pormpuraaw, exercise considerable influence and their groups are the basic operational units in community natural resource planning and management in sea and inland country on the southern Gulf Lowlands (Monaghan, 2005).

Focal leaders often exercise a quiet authority and can have a low and understated profile in community life so that, for instance in Kowanyama, they may appear to have little or no involvement in mainstream affairs or in the community council. Homeland groups are identifiable in township life as large co-resident groups with members often living in houses that are in close proximity to each other (Monaghan, 2005).

Other distinguishing criteria which can set homeland groups apart from the rest of the township include the following:

- $\quad$ stability of co-residence;

- a common surname;

- cognatic descent or clan affiliation to geographically contiguous areas of the landscape; and

- $\quad$ an age and gender balance in their membership that maintains a high reproductive potential for the group (Monaghan, 2005).

These criteria are not exclusive of each other and all criteria have to be satisfied before a homeland group can be confidently identified. For instance, a high density of a common surname in one part of the township is not necessarily indicative of the presence of a homeland group. Stability of residence is a particularly important indicator which can only be established by repeated censuses of household residents over many years. Three household surveys over a period of more than 15 years at Pormpuraaw have demonstrated that household mobility, a feature of Aboriginal community life, whereby people move between households over periods of weeks or months, is virtually absent in those households occupied by homeland groups (Monaghan, 2005). The national census cannot be used to profile homeland groups as they can only be identified at the household level (Monaghan, 2005). Their identification relies more on sociological than economic criteria as almost all community residents are participants in a welfare economy. Household or group 'wealth' is more evident demographically in terms of the number of women of reproductive age and in the number of young people who can act as future leaders for a homeland group and who can lobby for their interests in community life. Also from an economic perspective, a good distribution of children, working adults and pensioners may not necessarily endow advantages in terms of gross income but it can ensure access to a spectrum of welfare, wage and pension incomes 
at different intervals over the fortnightly household income cycle (Monaghan, 2005).

Homeland group membership, like traditional clan affiliation, forms a sociocentric or corporate identity for those people who have access to that place where their homeland is situated. There are also other people who have their own egocentric or personal rights to homeland country through traditional law but who are not members of a homeland group resident in that country. These latter rights may include important ritual links to country and even though they are not members of the homeland group, these people have to be acknowledged or consulted in land management issues. Their absence from group membership does not mean that they have a minor role in the affairs of homeland country. 'Ideological' or personal identities are heavily grounded in traditional law and in personal sensibilities of 'being'; the protocols of kinship and clan or homeland affiliation also enhance the unique sense of identity that each person has in Aboriginal society, and because of this individualism, a wide variety of opinions can be expressed in community political life. The contingencies that relate homeland group or sociocentric identity to personal or ideological identity are quite complex (Monaghan, 2005); at the very least it has to be understood that even though a person may not be a member of a homeland group that this does not necessarily exclude them from 'talking for country'. Conversely, a person may be a member of a homeland group and be actively involved in land management issues but have no authority to 'talk for country'.

\section{Implications of socio-political organisation for bushfire risk assessment}

There is a general resistance, in Cape York Peninsula at least, to any attempts at regional level organisation of issues that concern homeland country. Also, despite the widespread structural similarities in homeland group characteristics in Aboriginal Australia there are considerable differences in their modus operandi, even between two adjacent communities such as Pormpuraaw and Kowanyama, which preclude generalisations that might be made about fire management or regional scale peri-urban trends in remote Aboriginal communities. Fire behaviour and fire management practices can only be understood at the community scale.

The significance of social and group, and ideological and personal identities had to be continually borne in mind in the Pormpuraaw Natural Disaster Risk Management study (Monaghan \& Taylor, 2003) and thus community consultation was time-consuming as it had to include consideration of mainstream organisation in the community council and its agencies, and the 
various traditional and contemporary polities that make up the Aboriginal domain there. Many people in remote communities, and not just Aboriginal communities, will assume that the investigator has an understanding of local political life and local modes of social organisation because the community is their entire social universe and they know no other. Some may only visit a regional urban centre such as Cairns or Townsville for their birth and their death. Consequently, research prior to a visit or some time devoted to getting to know people is crucial before the start of any study as ignorance of the ways of local society on the part of 'outsiders' is often not tolerated in remote communities. Certainly, attempts to sample people in surveys or reference groups, as opposed to getting a complete census of opinion, that the author has observed in natural and cultural resource management projects over the years have rarely succeeded in eliciting adequate information or participation to make subsequent management plans work. Everybody has to be personally invited, and many people will be gratified by the invitation and will then defer to the authority of community leaders, otherwise any recommendations resulting from a study will be ignored.

'Mainstreaming' approaches adopted by regional planning strategies such as the Cape York Land Use Study (CYPLUS) to community consultation in the mid-1990s failed to recognise the diverse range of natural resource interests and the local polities that exist within communities in the Peninsula (Monaghan, 2005). Similar encounters between Aboriginal communities and State agencies involved in land and natural resource use planning and management have been reported elsewhere (Lane \& Chase, 1996).

Lane and Chase describe land use projects in the Lockhart River area of the east coast of the Peninsula, and report that despite the existence of formal planning processes for their inclusion, that there was often only a limited recognition of Aboriginal perspectives in the projects.

Too often the 'community' is seen simply as a homogenous unit, with a simple representative structure (the council) which somehow stands for or represents the varied local traditional interests in an unproblematic way (Lane \& Chase, 1996, p. 182).

The creation of formal planning structures should be the outcome of careful and detailed local ethnographic inputs, an appreciation of local historical factors and, more importantly, detailed knowledge about the politics of relevant Aboriginal communities and domains (Lane \& Chase, 1996, p. 173). 
Similar criticisms can be applied to academic studies of Aboriginal natural resource management where 'culture' is treated as an indeterminate constant or invariant background to management practice, and where the interactions between social practice and management practice are reviewed in terms of 'traditional' and 'modern' dichotomies, which are largely unrecognisable to the Aboriginal people with whom the author has worked.

At the same time consultation has to consider the multi-valence that attaches to statements about the landscape and the wide range of economic, mythological, kinship, or resource and ownership values that can be expressed for any place within it. Statements about country, either its physical or social properties, can rarely be taken at face value; sometimes, the social context of the informant has to be known before their statements can be interpreted. This distinction has to be borne in mind in natural hazard risk assessment as in other resource assessment studies when people talk about bushfire, are their comments grounded in the general knowledge of the physical environment and its seasonality that most people share, or does it have a phenomenological base in the totem affiliations, and stories or experiences that underpin personal identity? More importantly with questions related to management - does this person have the authority to make recommendations about risk management strategies in any particular area of the landscape? Such assessments are critical if management recommendations are part of the outcomes of a study.

Above all, the aims of a community consultation have to be presented clearly and unambiguously as there are barriers of language and vocabulary that sometimes have to be overcome so that participants may be able to contribute their own risk values or mitigation strategies to community planning confidently. The use of a geographical information system to store and display graphical media that represent landscapes and infrastructure and environmental hazards and that also presented risk models and local perspectives of the landscape based on recognisable landmarks has been particularly effective in natural hazard risk assessment in Pormpuraaw (Monaghan \& Taylor, 2003) and in natural resource assessment projects there and in Kowanyama (Monaghan, 2005).

The changes to Aboriginal community governance that are now taking place as a result of the introduction of shire councils and of ongoing native title determinations, mean that in the future the affairs of the township and the landscape will be dealt with by different bodies. The administration of the township will be by a council that operates under the various local government acts that apply to local authorities elsewhere in the State, and that of the landscape will be by homeland groups. The latter may function cooperatively as a lands trust with each group acting as a prescribed body 
corporate' under Queensland corporate law and federal native title legislation. Such arrangements already exist at Injinoo and Hope Vale, where land claim determinations under the Aboriginal Land Act 1991 (Queensland Government, 1991), the Native Title Act 1993 and the Native Title Amendment Act 1998 (Commonwealth of Australia; 1993, 1998) have already been made. This will lead to a higher profile and greater visibility for homeland leaders in public life and also one might anticipate a more densely occupied peri-urban landscape where the present day townships provide a service centre for the appropriate hinterland.

A modified version of this chapter was first published as Fire risk in Aboriginal peri-urban landscapes in North Australia: Case studies from western Cape York Peninsula, on a Centre for Disaster Studies web site in April 2004. 